\title{
Ecrire dans la matière digitale
}

Dans un article de 2016, Stéphane Crozat pose clairement la problématique du passage de «l'écriture qui veut imprimer à l'écriture qui veut programmer », soit la migration de l'écriture sur support papier à l'écriture électronique. Il distingue dans cette métamorphose deux types d'écritures numériques. D'un côté, l'écriture numérique «traditionnelle », qui «va nécessairement profiter de certaines fonctions spécifiques, mais de façon limitée, et essentiellement orientées vers le stockage et la circulation du contenu, plutôt que vers la production et la mise en forme des signes eux-mêmes $»^{1}$. Le maintien d'un tel type d'écriture numérique traditionnelle nous permet de nous inscrire, explique Crozat, dans les habitudes que nous avons apprises au cours de notre formation scolaire ; elle nous paraît plus fiable, car elle est déjà acquise ${ }^{2}$.

De l'autre côté de l'alternative se tient l'écriture computationnelle qui a pour « intention de programmer dynamiquement l'apparition des signes par l'exécution d'algorithmes et en fonction d'actions du lecteur $»^{3}$. Crozat la définit également par certaines expressions qu'il regroupe sous le vocable de tropismes du numérique, nous faisant renouer avec le terme mis à l'honneur par Nathalie Sarraute. Aux pressions technologiques, organisationnelles et personnelles imposées à l'écriture computationnelle s'ajoute celle des réseaux sociaux qui «font également pression sur les modes d'écriture; l'écriture collaborative synchrone ou asynchrone étant un exemple significatif. Or pour écrire à plusieurs, en réseau, il est nécessaire de mobiliser la dimension computationnelle de l'écriture, pour échanger des commentaires, comparer des versions... $»^{4}$. Au service de cette écriture computationnelle se trouvent des langages tels « LaTeX (LyX), HTML (wYMeditor) et les chaînes éditoriales XML

1 S. Crozat, «De l'écriture qui veut imprimer à l'écriture qui veut programmer », Revue de l'ENSSIB 4 (2016), p. 1-21 ; <http://www.enssib.fr/bibliotheque-numerique/notices/66840-de-lecriture-qui-veut-imprimer-al-ecriture-qui-veut-programmer $>$.

2 Crozat, «De l'écriture qui veut imprimer », p. 4.

3 Crozat, « De l'écriture qui veut imprimer », p. 3.

4 Crozat, «De l'écriture qui veut imprimer », p. 5 . 
(Scenari) », qui visent le principe dit du "WYSIWYM, 'What you see is what you mean', c'est-à-dire : 'Ce que vous voyez est ce que vous voulez dire' $»^{5}$.

Dans cet article, Crozat permet, avec le binôme écriture numérique traditionnelle / computationnelle, d'aller plus loin que Kenneth Goldsmith dans sa monographie Uncreative Writing. Managing Language in a Digital Age. Cette monographie suggestive date déjà de $2011^{6}$, mais a été traduite en français en 2018 par François Bon, Lécriture sans écriture du langage à l'âge numérique 7. Elle commence juste à faire son chemin dans la sphère francophone ${ }^{8}$. Goldsmith définit une écriture non créative qui n'est pas stricto sensu reliée à la culture digitale, mais qui est rendue possible à large échelle par celle-ci. En effet, dans l'écriture non créative, « on crée de nouvelles significations en reconfigurant des textes préexistants ${ }^{9}$, un processus intertextuel que l'auteur voit déjà à l'œuvre chez Joyce par exemple ${ }^{10}$. Cette uncreative writing entend se détacher de l'intentionnalité auctoriale, pour exprimer « une émotion jamais coercitive ni persuasive, comme si ces écrits la délivraient obliquement, sans préméditation, avec des sentiments qui jaillissent plutôt du processus d'écriture que de l'intention de l'auteur »"11.

Goldsmith a enseigné pendant plusieurs années cette écriture pour laquelle les étudiants devaient exclusivement réutiliser du matériel sans en créer $^{12}$,

Par opposition au WYsIWYG « What you see is what you get », Crozat, « De l'écriture qui veut imprimer », p. 6.

6 K. Goldsmith, Uncreative Writing. Managing Language in the Digital Age, Columbia University Press, 2011.

$7 \quad$ K. Goldsmith, Lécriture sans écriture du langage à l'âge numérique, F. Bon (trad.), Jean Boîte, 2018.

8 C'est toutefois en anglais qu'on perçoit le mieux le propos de Goldsmith. François Bon ne parvient pas à tenir tout au long du volume son choix de traduction de uncreative writing par l'écriture sans écriture : il doit parfois toute de même traduire « écriture non créative » pour que le lecteur s'y retrouve (Goldsmith, L'écriture sans écriture, p. 16-17 par exemple). Cela démontre qu'« écriture sans écriture » ne reflète pas complètement ce que Goldsmith a voulu dire par uncreative writing. Il est à relever que d'autres choix de traduction par Bon sont contestables : notamment virginal devient « original» (p. 40) et pregnant devient « riche» (p. 12).

9 Goldsmith, L'écriture sans écriture, p. 45.

10 Goldsmith, L'écriture sans écriture, p. 36 : «[Joyce] anticipe 'l'écriture sans écriture' par son geste d'assembler des mots, évaluant ceux qui relèvent du 'signal' et ceux qui relèvent du 'bruit', ce qu'il est bon de garder et ce qu'il est bon de laisser. Ce langage de l'évaluation et de la mesure est une des fonctions particulières des données et de l'information qui sont cruciales pour la santé de l'écosystème ».

11 Goldsmith, L'écriture sans écriture, p. 12.

12 Goldsmith, Uncreative Writing, p. 8: « For the past several years, I've taught a class at the University of Pennsylvania called 'Uncreative Writing'. In it, students are penalized for showing any shred of originality and creativity. Instead, they are rewarded for plagiarism, 
pour les conduire à l'expérience paradoxale d'une écriture qui leur paraissait au bout du compte plus créative que jamais ${ }^{13}$. L'uncreative writing de Goldsmith illustre donc clairement non pas l'écriture computationnelle, mais l'écriture numérique traditionnelle, selon la terminologie de Crozat, soit une utilisation facilitée et à large échelle de la réécriture intertextuelle.

Partant de Crozat donc, je souhaite conduire le binôme écriture numérique traditionnelle / computationnelle à une étape suivante de la description de la métamorphose de l'écriture lorsqu'elle s'unit à la matière digitale, et vérifier si elle pointe ultimement sur le corps, à l'instar des nouvelles technologies, selon la proposition de Jacques Derrida ${ }^{14}$. S'il est quelqu'un qui a scruté l'écrit et l'écriture dans toute sa densité, c'est bien Derrida, et pourtant, lorsqu'il tourne les regards vers ce futur qui advient, il désigne comme horizon le nouveau rapport du corps de l'homme aux machines. Ce troisième chapitre va scruter les métamorphoses de l'écriture digitale en gardant en point de mire ce lieu désigné par Derrida par-delà l'écriture livrée aux technologies, le corps.

En arrière-plan de notre réflexion se tiennent les descriptions médiatiques qui rapportent les avancées des rencontres entre corps et nouvelles technologies, comme les nombreux possibles suggérés par la reconnaissance faciale ${ }^{15}$. Que vaut encore l'écriture, quand bien même encodée dans les règles, face à la vague irrésistible de la culture digitale qui utilise le corps, voire se tient à même le corps, et marie oralité, images et sons avec le texte ? Se risquer à « écrire dans la matière digitale », titre de ce chapitre, est-ce donc accepter de voir l'écriture enclose, incorporée, encastrée, encapsulée, insérée - bref, embedded dans une matière qui ultimement pointerait vers le corps? Nous n'avons pas d'équivalent français univoque pour embed, qui regroupe tous ces sens évoqués en français et n'a plus rien à voir avec le concept d'incarnation, qui aura pendant des siècles représenté un modèle à succès d'intégration de l'extérieur dans le corps. La résistance d'embed à une traduction française univoque souligne, à mon sens, la nouveauté de ce qu'il met en scène.

Pour tenter de joindre les différents aspects de la problématique jusqu’à « ce nouveau rapport du corps de l'homme aux machines », ce chapitre 3 se mettra d'abord à l'écoute des entretiens radiophoniques donnés par Derrida en 1998 et

identity theft, repurposing papers, patch-writing, sampling, pondering, and stealing. Not surprisingly, they thrive».

13 Goldsmith, L'écriture sans écriture, p. 16-17.

14 Derrida, Sur parole, édition Kindle, 1. 484 ; cité dans l'Introduction, p. 3.

15 Voir RTs, « Reconnaissance faciale: des start-up suisses se lancent dans l'aventure », Téléjournal RTS de 12h145, 23 mai 2018, <http://www.rts.ch/play/tv/12h45/video/reconnais sance-faciale-des-starts-up-suisses-se-lancent-dans-laventure?id=9359971>. 
publiés en 1999 : ils permettront d'aborder les questions du rythme et du lieu de l'écriture digitale (2.1 et 2.2). Nous prendrons ensuite la mesure de la mutation qu'entraine le support d'écriture numérique en revisitant certains dispositifs classiques de l'écriture papier et imprimée, via quelques thématiques exemplaires de ce que l'on quitte et/ou qui mute : le « je » auctorial (3), la couverture et son dispositif (4.1), l'index et la référentialité (4.2). Pour illustrer ce qu'acquiert l'écriture digitale, nous aborderons la multimodalité et le code, deux innovations particulièrement marquantes (4.3). La conclusion nous ramènera à notre questionnement de départ, l'attraction de l'écriture digitale vers le corps (5). Ce chapitre aura ainsi permis d'explorer ce que veut dire « écrire dans la matière digitale », via un tour d'horizon synthétique.

\section{En quête du rythme et du lieu de l'écriture digitale}

\subsection{Parole et écriture au creuset du rythme}

Le premier des cinq entretiens de la série $A$ voix nue, conduits par Catherine Paoletti avec Jacques Derrida en 1998 pour France Culture, porte sur le parcours biographique du philosophe. C'est dans le second, «L'inscription et la trace », qu'il revisite les débuts de son parcours intellectuel, longue méditation sur l'écriture. Il se rappelle et nous rappelle qu'il est parti d'un questionnement mathématique et politique dans ses recherches, mais déjà «problématisait l'écriture » :

J'ai écrit mes premiers essais sur Husserl en les orientant vers la question de l'objectivité scientifique et des mathématiques: Cavaillès, Tan Duc Thao, et aussi la question marxiste. Au cours de ces premiers travaux, je cherchais, par fidélité à ce souci d'écriture, ce qui dans la phénoménologie husserlienne, pouvait me permettre de problématiser l'écriture. Où, où est-ce qu'il parle de l'écriture ? Qu'est-ce qu'il en fait ? Comment articuler ces questions de la science, de la phénoménologie et de l'écriture? J'ai trouvé ce lieu, dans l'Origine de la géométrie, que j'ai donc commencé à interpréter dans [un] premier mémoire [...], et que j'ai décidé de traduire aussitôt après ${ }^{16}$.

Pour parler de l'écriture, il faut un lieu. Alors même que dans ce premier écrit, Derrida ne thématise pas la question du support matériel de l'écriture, il lie 
d'emblée le discours sur l'écriture à la nécessité d'avoir un lieu pour en parler, ici l'Origine de la géométrie. Alors même qu'il revisite ce premier lieu d'où il a scruté l'écriture, le philosophe dessine les contours du programme épistémologique dont nous avons besoin pour réunir aujourd'hui les différents savoir fractionnés : l'écriture unit science et phénoménologie, à partir du lieu qu'est l'Origine de la géométrie d'Husser ${ }^{17}$. Cette perception de l'écriture se tient au creuset du lieu géométrique des savoirs, et vaut tant pour la culture imprimée que pour la culture numérique, bien que le lieu géométrique change de qualité dans l'univers digital (voir 2.2). Derrida ouvre ensuite la problématique à « la question qui continuait de [1]'intéresser : l'inscription littéraire. Qu'est-ce qu'une inscription? A partir de quel moment et dans quelles conditions une inscription devient-elle littéraire $?{ }^{18} \mathrm{Il}$ répond ainsi :

Il y a [...] une voix dans La carte postale qui dit : « Dès lors que ce que je t'écris devient littérature, je ne m'adresse plus à toi, et par conséquent je manque à ce devoir qui me commande de madresser à toi singulièrement ». La littérature peut appeler à la plus grande responsabilité mais elle est aussi la possibilité de la pire trahison. [...] La dépossession, c'est aussi le risque de ne même pas signer une déclaration d'amour. Au fond, ce n'est pas moi qui signe, dès que c'est lancé sur le marché littéraire, ça ne vient plus de moi, ça ne s'adresse pas à toi, la trace m'échappe, elle tombe dans le monde, elle est disponible pour un tiers, et c'est à cette condition qu'elle devient littérature, et c'est cette littérature qui pervertit mon rapport à toi. Le sujet qui signe ces envois ne cache pas son inquiétude ${ }^{19}$.

Ce que Derrida énonce ici concerne en premier lieu la littérature dans le cadre de la culture imprimée. Ce qu'il dit toutefois de la trace qui échappe - « la trace m'échappe, elle tombe dans le monde, elle est disponible pour un tiers » - rejoint profondément l'expérience que nous faisons avec ces mots que nous laissons aller en ligne. De fait, la version orale de la deuxième partie de ce passage se prête encore mieux au passage de la culture imprimée à la culture digitale. La voici, retranscrite à partir de l'enregistrement disponible en ligne du deuxième entretien, qui diffère de la version publiée sous forme de livre :

17 E. Husserl, L'origine de la géométrie, trad. J. Derrida, PUF, 1995.

18 Derrida, Sur parole, édition Kindle, l. 194-196.

19 Derrida, Sur parole, édition Kindle, l. 250-254. 
La dépossession, c'est aussi le risque de ne même pas signer une déclaration d'amour, n'est-ce pas. Ce n'est pas moi qui signe, c'est lancé sur le marché littéraire, et donc cela ne vient pas de moi, cela ne s'adresse pas à toi, et donc la littérature, le principe littéraire vient corrompre la relation singulière, absolue, que je cherche. Donc il y a cette inquiétude, cette confession, de la part du sujet qui signe ses envois, pas le livre, mais qui signe ses envois. Cette confession, à savoir je suis en train... dès que je parle, je trahis. Dès que je parle, la trace m'échappe, elle tombe dans le monde, elle est disponible pour un tiers, et par conséquent, c'est à cette condition qu'elle devient littérature, cette littérature qui pervertit, en quelque sorte, mon rapport à toi ${ }^{20}$.

Le registre de la parole, exclu de la version imprimée du passage, revendique ici clairement sa place $:$ « dès que je parle, je trahis [...et] c'est à cette condition qu[e la trace] devient littérature ». Parole et écriture sont mêlées ici dans un continuum : la trace est une parole qui devient littérature, et retrouve du coup son aspect de littérature parlée. Il est frappant que la version imprimée n'ait pas laissé sa place à ce continuum. C'est grâce à l'entretien oral que la parole crée sa brèche dans le processus littéraire. Avant la trace écrite, que le philosophe est en train de scruter dans son ambivalence, il y a la parole qui trahit à l'instant même où elle exprime, et prend forme ensuite dans l'écriture. Dans la culture digitale, l'écriture, par sa rapidité non seulement d'exécution mais de diffusion, retrouve de fait, matériellement, un rapport de proximité à l'oralité ; elle offre la possibilité de tester largement le continuum entre langage écrit et langage parlé21. Le défi est donc d'appréhender et de tester les différents rythmes de la parole et de l'écriture, dans la culture imprimée et dans la culture digitale. Jacques Derrida rattache ainsi notre responsabilité dans les transformations du monde qui vient à cette question du rythme, dans le penser et le lire :

Je ne peux pas séparer ce que vous appelez la pensée de l'invention singulière de la responsabilité prise par chacun. A son rythme - et là la question du rythme est importante en effet - il faut prendre le temps de penser et de lire. Alors naturellement, puisque je dis «lire», à la fois je

20 J. Derrida, « Philosophie et littérature : envie de faire les deux à la fois », 15 décembre 1998, 16min 51 à 17min 45 ; <https://www.franceculture.fr/2016-01-20-l-ecriture-a-la-trace-a-voixnue-jacques-derrida-25 $>$.

21 Cet aspect est mis en lumière dans le projet des etalks (etalk.vital-it.ch), voir C. Clivaz, C. Pache, M. Rivoal, M. Sankar, «Multimodal literacies and academic publishing: the eTalks", ISU 35 (2015/4), p. 251-258 ; <https://content.iospress.com/articles/informationservices-and-use/isu781>. Voir pour un développement le point 4.2 de ce chatpitre. 
vais être de ceux qui militent pour le livre, pour le temps du livre, pour la durée de la lecture, pour tout ce que la vieille civilisation du livre commande, mais en même temps je ne peux pas défendre le livre contre toute espèce de progrès technique qui aurait l'air de menacer le livre. Donc je vais faire les deux choses à la fois. Je veux être pour le livre et pour des moyens de communication, d'impression, de distribution, d'échanges qui ne dépendent pas simplement du livre, et il y a en a beaucoup. Et donc là entre les deux, je vais essayer d'inventer une stratégie qui sera singulière $^{22}$.

Dans cette citation, la gestion de la transition entre le monde du livre et le monde numérique culmine dans une stratégie singulière du rythme. Rien ne me semble plus exact, ni davantage coller à la réalité de tout ce que j'ai pu expérimenter ces dernières années en menant des projets de recherche en humanités numériques. Dans les entretiens, cette notion de « rythme » culmine dans la phrase mise en exergue dans l'introduction de ce livre et rappelée en introduction de ce chapitre, soit le nouveau rythme entre le corps de l'homme et les machines : en suivant Derrida, ce chapitre ira donc du rythme de l'oral et de l'écriture à celui de la rencontre des corps avec les machines et les technologies. Ce changement de rythme - lié à, dicté et imposé par la culture digitale - est l'un des facteurs qui conduisent à ce nouveau rapport du corps aux machines. D'une certaine manière, il n'y a rien de nouveau dans cette mise en évidence du rythme. Le concept de «rythme » dans la production de l'oral / écrit a notamment été scruté par le poète et linguiste Henri Meschonnic, à la croisée de la production littéraire et des performances sociales de l'auteur. Il écrit en 1982 :

Je définis le rythme dans le langage comme l'organisation des marques par lesquelles les signifiants, linguistiques et extra-linguistiques (dans le cas de la communication orale surtout) produisent une sémantique spécifique, distincte du sens lexical, et que j'appelle la signifiance : c'est-àdire les valeurs propres à un discours et à un seul. Ces marques peuvent se situer à tous les «niveaux» du langage : accentuelles, prosodiques, lexicales, syntaxiques. [...] Le sens étant l'activité du sujet de l'énonciation, le rythme est l'organisation du sujet comme discours dans et par son discours $^{23}$.

22 Derrida, Sur parole, édition Kindle, 1. 472-476.

23 H. Meschonnic, Critique du rythme. Anthropologie historique du langage, Verdier, 1982, p. 216-217. 
Le sujet est un corps-social-langagier qui s'exprime : comme chez Derrida, on a ici un continuum oralité-écriture qui se met en place. Cette notion de rythme sera également honorée dans une monographie de $1995^{24}$. Précurseur en son temps, Meschonnic semble décrire ce que nous expérimentons en ligne chaque jour, en particulier sur les réseaux sociaux, les vidéos professionnelles ou privées, où l'acte de s'exprimer est ramené désormais à l'oralité. A prendre en compte jusqu'aux adresses IP des appareils électroniques, on pourrait même dire qu'il n'y a plus aucune trace orale ou écrite enregistrée qui ne puisse être ramenée à l'activité d'un sujet d'énonciation. C'est cette mutation qui met au premier plan de la culture digitale le rythme comme structuration de notre communication. Cette multiplication des rythmes de la production du savoir affecte de plein fouet la recherche en sciences humaines, en en inversant les étapes, comme le relevait le magazine de Harvard en 2012. C'est tout un rythme qui est à recréer :

Les chercheurs ont l'habitude de commencer leurs projets en déterminant les questions de recherche pertinentes pour un champ donné, en lien à d'autres perspectives sur les mêmes sujets ; puis ils rassemblent, organisent et analysent les données ; et pour finir, ils font connaître leurs découvertes via l'enseignement et la publication. La recherche conduite dans un environnement numérique remet en question chaque étape de ce processus. Par exemple, en ce qui concerne le rassemblement et l'organisation des données ${ }^{25}$.

Le rythme digital met donc sens dessus-dessous la recherche, et remet en question le processus même de l'écriture, que Meschonnic n'opposait plus à l'oralité. De manière similaire, celui-ci n'opposait plus non plus la signification ou le sens aux sons. Pour le démontrer, il s'est appuyé sur le texte de la Bible hébraïque, attentif aux nombreuses marques d'oralité inscrites dans le texte. Comme le résume Pascal Michon,

24 H. Meschonnic, Politique du rythme, politique du sujet, Verdier, 1995.

25 J. Shaw, «Humanities Digitized. Reconceiving the study of culture», Harvard Magazine Mai-Juin 2012, p. 40-44 et 73-75; ici p. 42, <http://harvardmag.com/pdf/2012/05pdfs/0512-40.pdf > : « Scholars traditionally begin projects by figuring out what the good research questions are in a given field, and connecting with others interested in the same topics; they then gather and organize data; then analyze it; and finally, disseminate their findings through teaching or publication. Scholarship in a digital environment raises questions about every aspect of this process. For example, in gathering and organizing data ». 
Meschonnic puise également - et à son dire principalement - dans l'étude de l'écriture biblique et de sa traduction, réinterprétées à la lumière de Benveniste. Dans la Bible, au moins dans la version massorétique qu'il utilise, l'écriture ne s'oppose pas à l'oralité, le sens ne s'oppose pas au son. Le texte biblique s'appuie, comme tout discours, sur une syntaxe et un lexique, mais il fonctionne prioritairement autour d'un système d'accents, de contre-accents, de reprises en écho consonantiques et vocaliques qui sont autant de marques d'une oralité inscrite dans l'écriture même. Si bien que le sens n'y apparaît pas comme un produit de l'articulation syntaxique des seuls signifiés, mais comme la «signifiance » produite par le jeu de l'ensemble des signifiés-signifiants ${ }^{26}$.

Il est fondamental de se remémorer les liens ancestraux entre oralité et écriture pour appréhender la culture digitale, qui certes chamboule le jeu écritoral et y adjoint en prime le visuel. Ce processus, Neal Stephenson en souligne la présence y compris dans certains lieux de la culture informatique, dans son essai qui a fait date : In the Beginning... Was the Command Line. Il relève notamment la part d'oralité qu'on peut trouver y compris dans le code informatique de l'OS Unix, qu'il compare ni plus ni moins à l'épopée de Gilgamesh, un poème écrit en accadien entre 2800 et 2500 ans avant notre ère :

Windows 95 et MacOS sont des produits contraints par les ingénieurs au service de compagnies spécifiques. Au contraire, Unix n'est pas tant un «produit » qu'une histoire orale de la subculture hacker, compilée avec minutie. C'est notre épopée de Gilgamesh. [...] Unix est connu, aimé et compris par tant de hackers qu'il peut être recréé de zéro dès que quelqu'un en a besoin. [...] Unix s'est lentement agrégé autour d'un noyau simple et a acquis une sorte de complexité et d'asymétrie qui est organique, telle les racines d'un arbre, ou les branches d'une artère coronarienne ${ }^{27}$.

26 P. Michon, « Rythme, langage et subjectivation selon Henri Meschonnic », Rhuthmos 15 juillet 2010, p. 1-6; ici p. 2; <http://rhuthmos.eu/spip.php?article32>.

27 N. Stephenson, In the Beginning, édition Kindle, l. 937-947 : «Windows 95 and MacOS are products, contrived by engineers in the service of specific companies. Unix, by contrast, is not so much a 'product' as it is a painstakingly complied oral history of the hacker subculture. It is our Gilgamesh epic. [...] Unix is known, loved, and understood by so many hackers that it can be re-created from scratch whenever someone needs it. [...] Unix has slowly accreted around a simple kernel and acquired a kind of complexity and asymmetry that is organic, like the roots of a tree, or the branchings of a coronary artery ». Merci à Ivan Topolsky (SIB) pour cette référence. 
La mise en exergue de la notion de rythme dans les conditions d'expression de la pensée et les retrouvailles très vives de l'oralité et de l'écriture dans la culture digitale pourraient nous conduire à cet effet de « disruption » décrit par Bernard Stiegler et présenté au chapitre $2^{28}$. Bousculés dans notre rythme de pensée et d'écriture, c'est ici qu'il faut prendre à bras le corps la question du lieu de l'écriture digitale, de cette matière digitale et de son risque de nous conduire à la disruption. Ce face-à-face pourrait être une façon de tenir dans les pics de disruption digitale.

\subsection{Le lieu de l'écriture digitale}

Penser le lieu de l'écriture digitale demande d'abord d'affronter le contexte dans lequel ce lieu se déploie, celui de la disruption décrite par Bernard Stiegler. On a vu au chapitre 2 que ce dernier lui donnait une extension maximale et dramatique, comme « ce pouvoir automatique de désintégration réticulaire [qui] s'étend sur toute la Terre ${ }^{29}$. Cet état d'esprit se prolonge par son choix de citer un passage particulièrement sombre du poète René Char, écrit en 1951 : « Nous sommes ce jour plus près du sinistre que le tocsin lui-même, c'est pourquoi il est grand temps de nous composer une santé du malheur. Dût-elle avoir l'apparence de l'arrogance du miracle $»^{30}$. S'alignant sur ce tocsin poétique, Stiegler affirme toutefois que " pour continuer à lutter face à l'évidence du caractère absolument désespérant de la situation, c'est-à-dire : pour cesser de dénier l'état d'urgence dans lequel l'Anthropocène nous a menés et dont la disruption est l'extrémisation, il faudrait croire à la possibilité d'un miracle. [...] Répétons ici qu'un tel miracle est un rêve $»^{31}$.

Comment comprendre ce «miracle » et ce «rêve » évoqués en finale par Stiegler, et quelle résonance donnent-t-il à la disruption? Ou, dit autrement, jusqu'à quel point faut-il faire une lecture dramatique du contexte global dans lequel nous voulons penser le lieu de l'écriture digitale ? Pour bien comprendre cette association du miracle au rêve chez Stiegler, soulignons que le rêve est pour lui éminemment positif. Adossant au rêve de Foucault la folie de la croix de l'apôtre Paul, telle que transmise par L'Eloge de la folie d'Erasme ${ }^{32}$, il propose la notion de rêve comme lieu du retournement final de son livre, dont on pressent dès les premières pages qu'il lui faudra bien une échappée moins

\footnotetext{
28 Voir chapitre 2, p. 50-51.

29 B. Stiegler, Dans la disruption. Comment ne pas devenir fou?, Les liens qui libèrent, 2016, p. 22 ; cité au chapitre 2, p. 49.

30 R. Char, A une sérénité crispée, Gallimard, $195^{1}$; cité, sans la pagination, par Stiegler, Dans la disruption, p. 400.

$31 \quad$ Stiegler, Dans la disruption, p. 433-434.

$3^{2}$ Stiegler, Dans la disruption, p. 412-413.
} 
sombre, à un moment ou l'autre. Le rêve comme «possibilité du miracle » répond chez Stiegler à la « santé du malheur » qui aurait « l'arrogance de l'apparence du miracle » de René Char.

Dans sa très longue conclusion de trente-sept pages sur le rêve, Stiegler souligne que « seul le nouveau rêve noétique peut encore nous sauver », et que le rêve est « la condition de la politique » 33 . Mais non sans rappeler qu'il nous fait courir le risque de la folie : « c'est le rêve noétique qui engendre le pharmakon, lequel, comme $\tau \dot{\varepsilon} \chi \nu \eta$, peut rendre fou ${ }^{34}$. Cet enchaînement entre rêve noétique, pharmakon, technè et folie est à mon sens à observer avec la plus grande attention: Stiegler touche ici au cœur de la «machinerie » de la disruption, cette computing machinery présente dans l'article de Turing, mais dans le titre seulement ${ }^{35}$. Face à cette machinerie, y a-t-il moyen d'utiliser la forme motrice du rêve noétique, tout en se prémunissant de la folie/disruption que peut provoquer le pharmakon / technè ? L'avenir nous dira si nous y parvenons un tant soit peu.

Dans ce contexte marqué par la machinerie de la disruption, je propose de plonger dans nos racines culturelles mémorielles pour cartographier le lieu de l'écriture digitale. Tout comme nous l'avons vu avec la présence de l'oralité dans l'écriture - de Gilgamesh à Unix en passant par la Bible hébraïque -, il est en effet bienfaisant de contempler des continuum culturels, philosophiques et épistémologiques, alors que nous sommes plongés sans cesse dans la disruption, dans ce qui sonne comme une nouveauté sans fin face à nos usus, notamment ceux qui nous ont été transmis lors de notre éducation scolaire. C'est donc dans le continuum de l'héritage de la culture grecque, et platonicienne en particulier, que je vais puiser de quoi penser le lieu de l'écriture digitale, via les thématiques de la pierre d'Héraclée, puis de la khôra.

La pierre d'Héraclée, ou pierre magnétique, fascinait dans l'Antiquité. Elle est mise en scène et commentée dans un ouvrage de jeunesse de Platon sur la technè, Ion ${ }^{36}$. Platon y considère la technè à la fois comme une science, un savoir technique et un savoir-faire, donc de manière plus large que ne le fait Stiegler. Dans cet ouvrage, sous-titré De L'Iliade, il s'agit une fois encore du

\footnotetext{
33 Stiegler, Dans la disruption, p. 285.

34 Stiegler, Dans la disruption, p. 411.

35 Voir chapitre 2, p. 82.

36 Pour un premier commentaire de ce passage, voir cet etalk, en ligne : C. Clivaz, « Mais où est le corps? L'Homme augmenté comme lieu des Humanités Digitales », dans L'Homme Augmenté, P. Bornet, C. Clivaz, N. Durisch Gauthier et É. Honoré (éd.), Swiss Institute of Bioinformatics, Lausanne, 2015, <https://etalk2.sib.swiss/?dir=Clivaz\#0> ; 34minı3. Cette thématique a aussi fait l'objet d'une conférence au Groupe Vaudois de Philosophie, le 15 janvier 2015, à Lausanne, non publiée.
} 
face-à-face du philosophe avec la poésie, la poétique, la divinisation, la folie (mania), auxquelles s'opposerait le discours de la vérité prononcé par Socrate, le monde du logos. Ion, rhapsode homérique, va se trouver taxé d'«herméneute » par Platon, ce qui n'est pas un compliment sous son stylet : en effet, pour le philosophe, la pierre magnétique illustre de quelle manière s'assimilent inspiration poétique, divinisation et folie, au point que Ion, poussé dans ses retranchements, va s'écrier : «Tu argumentes bien Socrate; mais je serais étonné, cela dit, si tu argumentais assez bien pour me convaincre que c'est la possession et la folie qui me donnent de bien commenter Homère » (Ion $536 \mathrm{~d})^{37}$. Socrate lui avait en effet proposé le raisonnement suivant :

Ce n'est pas un savoir technique que tu as en toi quand tu commentes bien Homère, [...] mais c'est une force divine qui t'anime, à la manière de cette pierre qu'Euripide a nommée magnétique, et que tout le monde appelle pierre d'Héraclée. En effet, cette pierre n'attire pas seulement les anneaux de fer, mais elle transmet aux anneaux une force qui leur donne le même pouvoir que la pierre, celui d'attirer d'autres anneaux : c'est ainsi, parfois, que se forme une très longue série d'anneaux de fer suspendus les uns aux autres, et c'est de la pierre en question que vient la force qui les tient tous suspendus.

De manière semblable, la Muse fait qu'on est habité par le dieu : ou elle le fait directement, ou ceux qui sont ainsi habités forment une série à laquelle d'autres sont suspendus dans l'enthousiasme divin. Car tous les poètes épiques, j'entends les bons, ce n'est pas parce qu'ils ont un savoir technique, mais parce qu'ils sont habités et possédés par un dieu, qu'ils récitent tous leurs beaux poèmes ; et les bons poètes lyriques tout autant (Ion 533e-534a $)^{38}$.

Ce passage est capital pour comprendre aujourd'hui ce qui advient dans la culture digitale, lorsque nous projetons dans le cloud, la nuée ou le ciel, ce qui est de l'ordre de l'électronique ${ }^{39}$. Le point de vue platonicien développé par Socrate postule une dichotomie entre savoir technique et inspiration poétique, assimilée ici à la force magnétique, perçue comme «magique » plutôt que « technique ». Le poète est le premier anneau qui transmet la force magnétique de l'inspiration, le rhapsode se tient au milieu et le spectateur en queue de liste. Inspiration et mania sont reliées telles des anneaux l'une à l'autre par

Platon, Ion et autres textes. Poésie et philosophie, J. Lauxerois (éd. et trad.), Pocket, 2008, p. 51.

$38 \quad$ Platon, Ion, p. 46.

39 Voir chapitre 1, p. 29-30. 
la force de la pierre magnétique. Autrement dit, ce dont Platon ne veut pas, il l'expulse comme de l'hors-humain, du «magnétisme», de la force obscure, maladive, de la folie, opposée au savoir technique : mieux vaut que l'humain ne tente pas le contact à la matière électrique ou magnétique qui pourrait le conduire à la possession, à la folie. C'est ce que j'appellerai le topos de la «répulsion de la pierre d'Héraclée », qui n’a cessé de hanter l'histoire de la philosophie occidentale jusques et y compris dans la représentation stieglérienne du pharmakon - qui pourrait conduire à la folie disruptive ${ }^{40}$.

Le point de vue défendu par Socrate dans Ion informe toujours, à mon sens, notre rapport à l'informatique et à l'internet. Pour surmonter la dichotomie engendrée par la répulsion au magnétisme, réel et symbolique, le défi est de parvenir à remettre ensemble le « savoir technique » et ce magnétisme, si souvent associé à nos fantasmes d'immédiateté et de magie. Sans surmonter, au moins en partie, cette dichotomie culturelle héritée, il sera difficile de faire face en profondeur à ce lieu d'écriture et de pensée qu'est la matérialité digitale. L'entreprise s'annonce de longue haleine: je me contenterai ici d'esquisser quelques pistes. Commençons par observer ce qui s'est joué autour de la question de la majuscule à maintenir ou à enlever au mot « internet ».

La discussion à ce propos a été vive entre 2015 et 2016. Le $1^{\mathrm{er}}$ juin 2016, l'Associated Press Stylebook, «bible grammaticale et linguistique pour les journalistes américains ${ }^{41}$, a en effet décidé de faire perdre sa majuscule à internet. Dans le camp des opposants, on trouve par exemple Bob Wyman, expert chez Google, qui a toujours milité pour garder la majuscule afin de différencier l'Internet de l'AR PANET, ce premier réseau internet ${ }^{42}$. Dans le camp des pour, Thomas Kent, éditeur de l'Associated Press, s'enthousiasme dans le New York Times en 2016 du fait qu'internet, pour les jeunes, serait « comme l'eau », expliquant

40 D'autres modalités de discours sur le magnétisme, et son rapport complexe à l'humain, ont hanté l'histoire culturelle occidentale, via le mesmérisme et autres médiumnités. Pour une documentation et un enthousiasme extrême sur la question, voir la thèse défendue en Sorbonne par le sociologue et parapsychologue Bertrand Meheust : B. Meheust, Somnambulisme et médiumnité (Les empêcheurs de penser en rond), vol. 1: le défi du magnétisme; vol. 2: le choc des sciences psychiques, Editions Synthélabo, 1999.

41 R. Goument, «L'internet perd sa majuscule », L'Obs Rue 89, 26 mai 2016, <https://www. nouvelobs.com/rue89/rue89-internet/20160526.RUE2996/internet-perd-sa-majuscule. html>. Voir mon article de blog dans le journal Le Temps : C. Clivaz, «Internet avec ou sans majuscule, ou nos fantasmes d'omniprésence », Le Temps 4 juin 2016, <https://blogs. le temps.ch/claire-clivaz/2016/06/o4/internet-avec-ou-sans-majuscule-ou-nos-fantas mes- domnipresence/>.

42 L. Vinogradoff, « Faut-il mettre une majusculte à 'Internet'? », Le Monde, blogs, 4 avril 2016, <http://bigbrowser.blog.lemonde.fr/2016/04/04/faut-il-mettre-une-majuscule-a-in ternet/>. 
la présence de la majuscule antérieure à l'idée qu'on aurait d'abord perçu internet comme « un lieu physique avec un nom propre », tel Rome ou Berlin; il ajoute qu'il «ne pense pas que beaucoup de personnes le voient encore ainsi » ${ }^{43}$.

Si pour Kent la perte de la majuscule à internet en dit l'omniprésence, il y a de quoi rester songeur : on se dédouanerait ainsi des limites physiques des câbles électriques et autres qui permettent à internet d'être effectif. Mais des arguments de toute-présence peuvent tout aussi bien se trouver sous la plume de ceux qui défendent la majuscule à internet, tel le philosophe Paul Mathias. Dans une interview de 2015, Mathias affirme qu'« Internet désigne plusieurs réseaux comme l'Univers désigne plusieurs galaxies. Dans ce cas, pourquoi retirer l'article ? On devrait écrire - et dire - 'l'Internet' et doubler la majuscule d'un déterminant »; et Mathias de conclure : « C'est drôle, il n'y a qu'un mot en français où l'on utilise une majuscule et pas de déterminant sans que ce soit véritablement un nom propre : c'est 'Dieu' ${ }^{44}$. La boucle est bouclée : on rejoint ici l'atmosphère instaurée par le vocabulaire d'« ordonner » et d'« ordination » que Jacques Perret reconnaissait graviter autour d'« ordinateur», son choix de traduction pour computer en $1955^{45}$.

La manière dont nous sollicitons les noms et les mots révèle ce qui est en jeu, même si ce jeu n'est, et de loin, pas conscientisé par tous les chercheurs ${ }^{46}$. A voir se répéter l'assimilation d'internet au divin ou à l'omniprésence, on mesure que nous ne sommes pas sortis de la fascination/répulsion pour la pierre d'Héraclée. Cette relation amibiguë s'exprime dans les propos rassemblés cidessus autour de la notion de « lieu » que serait ou ne serait pas internet: on veut en faire un lieu à la dimension de l'univers (Mathias), sans l'assimiler à un lieu physique (Kent), mais doué de la flexibilité et de l'omniprésence qu'on peut vouloir accorder à l'eau (Kent). Ces rêves du cloud ne semblent guère aptes à laisser la place à la définition matérielle et physique d'internet. Une fois conscients qu'il nous revient de surmonter notre répulsion pour la pierre d'Hé-

43 J. E. Bromwich, «Bulletin! The 'Internet' Is About to Get Smaller », New York Times 24 Mai 2016, <https://www.nytimes.com/2016/05/25/business/media/internet-to-be-lowercasein-new-york-times-and-associated-press.html?_r=2>.

M. Zafimehy, « internet ou Internet? », L'Obs Rue 89, 31 juillet 2015, <https://www.nouve lobs.com/rue89/rue89-internet/20150731.RUE0057/internet-ou-internet.html>.

45 Voir chapitre 1, p. 30.

46 Félix Tréguer a défendu à fin 2017 une thèse de 596 pages sur internet - avec majuscule, mais sans évoquer à aucun moment la discussion sur la majuscule à mettre ou non à ce nom : F. Tréguer, Pouvoir et résistance dans l'espace public : une contre-histoire d'Internet (XV'-XXI ${ }^{e}$ siècle), EHESS (Paris), 2017, <https://halshs.archives-ouvertes.fr/tel-01631122>. 
raclée, comment appréhender le lieu digital pour ne pas dupliquer sans fin nos projections de toute-puissance sur cet espace?

C'est ici qu'il est utile d'ouvrir à nouveau le bagage de la culture antique pour trouver un nom que nous véhiculons depuis longtemps pour représenter quelque chose comme un lieu qu'on ne connaît pas, qui échappe à notre capacité à décrire, et que pourtant nous voyons exister : la khôra grecque, commentée dans le Timée par Platon, un texte relu par Jacques Derrida dans Khôra $(1993)^{47}$, le dernier volet de la triade Passions ${ }^{48}$ - Sauf le nom - Khôra. Comme Derrida le résume, le nom de khôra signifie «lieu», «place», «emplacement », «région», «contrée », « ou ce que la tradition appelle les figures comparaison, image, métaphores - proposées par Timée lui-même ('mère', 'nourrice', 'réceptacle', 'porte-empreinte'), les traductions restent prises dans des réseaux d'interprétation ${ }^{49}$. Aussi le féminin de khôra n'est-il pas à surdéterminer : khôra, utilisé quasi comme un nom propre par Derrida, est en fait un tritos genos, « ni sensible, ni intelligible, 'comme' une mère ou une nourrice $»^{50}$. C'était la possibilité d'un lieu de ce type que Turing ouvrait dans son jeu de l'imitation avec le personnage $\mathrm{C}$, dispensé d'être masculin ou féminin ${ }^{51}$.

Pour lever le regard au-delà de Platon, on peut souligner que la khôra est souvent mentionnée dans la culture grecque, dans diverses acceptions, notamment comme un lieu qu'on sait exister, mais où sont allés très peu de gens, et dont sont revenus encore moins. Par exemple, c'est le cas du Penjab dans les récits des conquêtes d'Alexandre le Grand, cette khôra où des morsures de terribles serpents peuvent provoquer une sueur de sang en faisant agoniser, comme le raconte l'historien Diodore de Sicile au premier siècle avant notre ère ${ }^{52}$.

Cette khôra, contrée inintelligible, a en prime un aspect éminemment politique, qui nous invite d'autant plus à puiser dans ce matériau culturel

47 J. Derrida, Khôra, Galilée, 1993.

48 J. Derrida, Passions, Galilée, 1993.

49 Derrida, Khôra, p. 23-24.

$50 \quad$ Derrida, Khôra, p. 53 .

$51 \quad$ Voir Turing, «Computing Machinery and Intelligence», p. 433 : « [Le jeu de l'imitation] est joué par trois personnes, un homme (A), une femme (B), et quelqu'un qui interroge (C) qui peut être d'un sexe ou l'autre ». Cité au chapitre 2, p. 75.

$5^{2}$ Diodore de Sicile, La Bibliothèque historique, M. Casevitz et al. (éd.), Belles-Lettres, 1976, ici 17, 90, 5-6, p. 126 : «La contrée ( $\left.\chi \omega^{\omega} p \alpha\right)$ possédait aussi une foule de serpents de petite taille, étrangement bariolés. Les uns montraient en effet des zébrures ressemblant à du bronze; d'autres avaient une crête velue, formant chevelure. Leur morsure provoquait une mort rapide. Celui qui était atteint, de terribles douleurs le tenaient, une sueur sanglante le couvrait ! ». Cité dans Clivaz, L'ange et la sueur de sang, p. 416. 
millénaire pour mettre à nu nos sentiments et projections suscités par le lieu « internet». En effet, toujours selon Derrida, «il n'y a, au sujet de khôra, ni théologie négative ni pensée du Bien, de l'Un ou de Dieu au-delà de l'Etre. Cette incroyable et improbable expérience est aussi, entre autres dimensions, politique. Elle annonce une pensée, plutôt, sans la promettre, une mise à l'épreuve du politique $»^{53}$. L'internet-khôra se donne comme ce tritos genos qui met à l'épreuve le politique ${ }^{54}$, qui nous est « comme » une mère tantôt nourricière, tantôt dévorante, «comme » une empreinte-réceptacle ni sensible, ni intelligible. Et pourtant il faut la penser, l'affronter, et surmonter la répulsion de la pierre d'Héraclée suscitée par ce lieu, en faisant face jusques aux conséquences de la modification de nos cerveaux par l'usage des smartphones ${ }^{55}$.

Pour appréhender cette modification même des corps inscrite dans le programme de la khôra digitale, il nous faudra peu à peu nous habituer à troquer ce que nous nommons « hybridité» contre la « porosité »56 : en effet, le flux électrique transite désormais entre notre corps et la machine, via ce que nous écrivons du bout des doigts. L'idée d'impossibilité logée au cœur de l'hybridité - où hubris signifie «l'excès »-, s'éloigne chaque jour davantage pour nous mettre face à une multitudes de possibles auxquels nous devenons bien trop vite et bien trop souvent « poreux » : le « je » de celle ou celui qui écrit dans la matière digitale est mis à mal par cette porosité et va devoir se recomposer une résistance intérieure, comme nous allons le voir au point suivant. Pour Violaine Houdart-Merot et Anne-Marie Petitjean, l'écriture numérique est un « espace de porosité $»^{57}$ : c'est la reconnaissance de la khôra digitale comme nouveau lieu, condition, état d'écriture.

53 Derrida, Khôra; cette citation se trouve à la fin de la quatrième page du feuillet Prière d'insérer, ajouté au volume.

54 L'impact d'internet sur le politique n'est pas sans susciter des craintes multiples, tel le cri du cœur de l'écrivain Philippe Rahmy, juste avant son décès: P. Rahmy, Propositions démocratiques/Democratic proposals, Editions d'En Bas, 2017. Pour une synthèse journalistique de la problématique en Suisse : L. Bailat, « Comment le ciblage des citoyens sur les réseaux change la donne pour les partis politiques », Le Temps 31 octobre 2017, <https:// www.letemps.ch/suisse/ciblage-citoyens-reseaux-change-donne-partis-politiques $>$. Pour une réflexion de fond, voir le magistral article d'A. Rouvroy, « La vie n'est pas donnée », Le gouvernement des données. Etudes Digitales 2 (2017), p. 196-217. Il est commenté au point 3.2 de ce chapitre.

55 Voir Gindrat et al., « Use-Dependent Cortical Processing », cité dans l'Introduction, p. 4-5.

56 Voir Clivaz, « Mais où est le corps? », <https://etalk2.sib.swiss/?dir=Clivaz\#66> et ss.

57 Houdart-Merot - Petitjean, «Introduction », <https://www.u-cergy.fr/fr/laboratoires/ago ra/cahiers-d-agora/numero-1/introduction.html $>$. 
Surmontant la répulsion d'Héraclée, lucides devant notre porosité à la pierre magnétique, faisons à notre avantage mémoire de la caisse de résonance antique de la khôra. Elle nous donne un mot, un nom pour penser ce lieu qu'on n'arrive pas encore à décrire, qu'on pressent plus qu'on ne connait, tout en le sachant exister et en éprouvant ses effets. Nous voici assignés à écrire, à lire, à réécrire dans cette khôra digitale. Voyons ce que cela provoque pour quelquesuns des points classiques du dispositif de l'écriture pré-digitale.

C'est tout un art d'évaluer l'influence de la culture digitale et ses transformations, sans les surestimer ni les sous-estimer. De fait, le « je » d'auteur ou «je » auctorial est en mutation continue depuis l'après-Seconde Guerre Mondiale, notamment dans son rapport à la catégorie des genres littéraires et à l'expression des émotions. En me basant sur cette analyse, je mettrai en évidence en 3.1 et 3.2 ce qui me paraît être deux effets particulièrement importants de la culture digitale sur le «je » d'auteur : d'une part la porosité de ce « je » d'auteur au lieu digital, accentuée par l'aspect multimodal de cette culture, et d'autre part la manière dont le «je » d'auteur est mis à mal par la contrainte algorithmique, voire sa violence, la gouvernementalité algorithmique s'en prenant à la «puissance » des sujets, comme nous le verrons avec Antoinette Rouvroy ${ }^{58}$. Face à cette violence, l'argument final de cette partie sera d'encourager le «je » auctorial à se construire, en s'appuyant sur le for intérieur de la personnalité (3.3).

\section{1 «Je» auctorial de l'historien, genres littéraires et émotions}

$\mathrm{Au}$ sortir de la Seconde Guerre mondiale, l'expression du «je » de l'historien tel que posé dans la modernité sous la houlette de Léopold von Ranke, père de l'historicisme allemand - va entrer dans une période de remise en question longue et fondamentale. Tout l'effort de Ranke aura été de dissocier l'histoire de la poétique et de la rhétorique, un lien qu'il refuse même de lire chez les anciens : «On ne peut pas exiger d'une histoire le libre déploiement que cherche au moins la théorie dans une œuvre poétique, et je ne sais pas si on croit à bon droit avoir trouvé une telle théorie dans les œuvres des maîtres

$5^{8}$ Rouvroy, « La vie n'est pas donnée », p. 198. 
grecs et romains » ${ }^{5}$. Rompant avec toute émotionnalité, le « je » de l'historien se doit pour Ranke d'énoncer une histoire farblos et unschön, sans couleur et inesthétique ${ }^{60}$.

Et pourtant, n'en déplaise à l'historien allemand, «l'histoire a longtemps été considérée comme un genre et une part des Belles-Lettres ${ }^{61}$, et ne va oublier sa littérarité qu'à l'orée de la modernité, par paliers successifs ${ }^{62}$. Au sein de cette évolution, Ranke se montre représentatif et fer de lance de la division que l'historicisme du $19^{\mathrm{e}}$ siècle instaure entre la littérature et l'histoire, « constituée tout à fait en discipline autonome, et [qui] dès lors n'est plus considérée comme l'un des genres littéraires ${ }^{63}$. L'achèvement de cette division établie désormais entre histoire et littérature se laisse vérifier dans l'ouvrage du critique littéraire Léon Levrault sur l'histoire, publié en 1930 dans la série des Genres littéraires : cet ouvrage est en lui-même l'aveu de l'impossibilité de qualifier encore l'histoire de "genre littéraire » dans un contexte historiciste, où Clio l'a emporté sur les autres Muses. C'est pourquoi Levrault conclut ainsi son ouvrage :

Et, chez nous, héritiers de l'esprit grec et du génie grec, voilà bien l'écueil éternel! Nous exigeons l'impeccable science, avec toute sa sévérité, et nous ne sommes satisfaits que si l'art le plus pur nous a inondés de ses rayons. Quelle impasse pour nos historiens ! [...] Nous avons eu des chroniqueurs, des mémorialistes, des historiens. L'historien, voilà ce qui nous manque encore ! Où donc est-il celui-là qui, sur un sujet bien choisi, unira les qualités de Thierry et de Michelet, de Thiers et de Fustel ? Voilà ce qu'il faut aux Français. Et si jamais il existe, il ne sera point seulement notre historien: il sera véritablement l'Histoire !64

Telle est la vision qui préside à une «Histoire» sévère de l'« impeccable science », à l'orée de la Seconde Guerre mondiale, dont la digestion va cham-

59 L. von Ranke, Geschichte der Germanischen Völker. Fürsten und Völker die Geschichte der romanischen und germanischen Völker von 1494 bis 1514, W. Andreas (éd.), Emil Vollmer Verlag, 2000, p. 4: «Man kann von einer Historie nicht die freie Entfaltung fordern, welche wenigstens die Theorie in einem poetischen Werke sucht, und ich weiss nicht, ob man eine solche mit Recht in den Werken der griechischen und römischen Meister gefunden zu haben glaubt ».

6o Ranke, Geschichten, p. 4.

$61 \quad$ P. Aron, D. Saint-Jacques et A. Viala (éd.), Le Dictionnaire du Littéraire, PUF, 2002, p. 264.

62 Voir Clivaz, L'ange et la sueur de sang, p. 22-24.

63 Aron, Saint-Jacques et Viala (éd.), Dictionnaire du littéraire, p. 265.

64 L. Levrault, L'histoire. Les genres littéraires, Librairie Mellottée, 1930, p. 155-156. 
bouler à nouveau la perception de cette discipline, qui se redécouvrira «écriture de part en part», comme l'exprimera Paul Ricœur en $2000^{65}$. En me permettant de renvoyer le lecteur à L'ange et la sueur de sang pour la présentation complète de ce parcours de l'histoire en lien aux genres littéraires ${ }^{66}$, je pointerai ici ce qu'il arrive au « je » de l'historien, ce qui le heurte de front. Le bannissement des émotions dans le langage historique s'enracine dans les écrits de Jean-François Marmotel, qui en avait appelé en 1787 au rejet des émotions en histoire, ainsi quà la transparence du langage historique ${ }^{67}$. Léopold von Ranke ne fait que mettre un point d'orgue à cette visée ${ }^{68}$. Pour rompre avec cette vision des choses, il faudra qu'en pleine Seconde Guerre Mondiale, Walter Benjamin, à la veille de fuir Paris persécuté en raison de son identité juive, s'empare de Flaubert qui proclame qu'il faut être triste pour raconter l'histoire de Carthage dans Salammbô :

[L'empathie] naît de la paresse du cœur, de l'acedia, qui désespère de saisir la véritable image historique dans son surgissement fugitif. [...] Flaubert, qui l'a connue, écrit : «Peu de gens devineront combien il a fallu être triste pour [entreprendre] de ressusciter Carthage ». La nature de cette tristesse se dessine plus clairement lorsqu'on se demande à qui précisément l'historiciste s'identifie par empathie. On devra inévitablement répondre : au vainqueur ${ }^{69}$.

Benjamin pointe ici les liens de l'historicisme avec les vainqueurs. C'est exactement ce verrou qui va sauter dès l'après-Seconde Guerre Mondiale, jetant dans une tourmente de réflexions les historiens quant à leur tâche. Une fois le siècle traversé, François Hartog se trouvera à la questionner ainsi, l'articulant au point de vue des vainqueurs et des vaincus : «alors que l'histoire des vainqueurs ne voit que d'un seul côté, le sien, celle des vaincus doit, pour comprendre ce qui s'est passé, prendre en compte les deux côtés. Une histoire des témoins ou des victimes peut-elle faire droit à cette exigence qu'emporte avec

65 P. Ricœur, La mémoire, l'histoire, l'oubli (L'ordre philosophique), Seuil, 2000, p. 302.

66 Clivaz, L'ange et la sueur de sang, part. p. 17-33 et 132-145; je remercie chaleureusement l'éditeur Paul Peeters d'avoir donné son accord à la publication d'un résumé du contenu de ces pages dans ce point 3.1.

67 J.-F. Marmotel, Eléments de littérature, vol. 2, Paris: Firmin Didot, [1787] 1846, p. 247.

68 Ranke, Geschichten, p. 4.

69 W. Benjamin, «Sur le concept d'histoire », dans Walter Benjamin. OEuvres, M. de Gandillac - R. Rochlitz - P. Rusch (trad), vol. 3, Gallimard, 2000, p. 427-443; ici thèse viI, p. 436. 
elle le très vieux mot d'historia? $»^{70}$ En effet l'« histoire » garde en son sein le souvenir étymologique de l'istôr grec, l'arbitre, et jusqu'à la prétention de cet arbitre au point de vue divin : à la suite de Benveniste, François Hartog rappelle en effet les racines étymologiques d'istôr, «formule du serment : Istô Zeus, que Zeus soit témoin ${ }^{71}$.

La tourmente du $20^{\mathrm{e}}$ siècle a déconstruit cette posture de l'historien capable d'arbitrer depuis un point de vue omniscient. L'historien contemporain a renoncé à son attache univoque, scellée sous le règne de l'historicisme, au point de vue des vainqueurs, et se retrouve à hésiter devant la manière dont il convient de dire « je », devant la manière de renouer avec la littérarité de l'histoire, et le langage émotionnel. C'est ce type de défi qu'affronte l'historien néerlandais Frank Ankersmit à l'orée du $21^{\mathrm{e}}$ siècle, considérant que le mémorial de la Shoah ne doit être ni overcoming of the past, ni une réconciliation avec les horreurs du passé, mais doit rester « une maladie, un désordre mental à propos duquel nous pourrions ne jamais cesser de souffrir »; un tel génocide en effet « reste à jamais un possible dans l'histoire future de l'humanité ${ }^{72}$. A ce point de vue dramatique, Paul Ricœur tentera d'opposer l'idée de «l'oubli de réserve » et de la «mémoire heureuse », un pari qui ne va pas sans risque, comme je l'ai commenté ${ }^{73}$.

Face au duel entre mémoire qui ne cesse de faire souffrir et mémoire heureuse, je préfère à nouveau solliciter la mémoire antique. L'historien François Hartog relit Homère à la suite d'Hannah Arendt ${ }^{74}$, et nous remet en face de la première rencontre entre histoire et poétique : alors que chante l'aède Démodocos au banquet du roi Alcinoos, Ulysse se lève et lui reproche de rendre de

$70 \quad$ F. Hartog, « Le témoin et l'historien », Gradhiva 27 (2000), p. 1-15; ici p. 14 ; republié dans F. Hartog, Evidence de l'histoire (Foliohistoire), Gallimard, 2007, p. 236-266.

$71 \quad$ F. Hartog - M. Casevitz, L'histoire d'Homère à Augustin: préfaces des historiens et textes sur l'histoire réunis et commentés par François Hartog, traduits par Michel Casevitz (Points Essais 388), Seuil, 1999, p. 36.

72 F. R. Ankersmit, Historical Representation (Cultural Memory in the Present), Standford University Press, 2001, p. 193.

73 P. Ricœur, La mémoire, l'histoire, l'oubli, par exemple p. 65 et 595; Clivaz, L'ange et la sueur de sang, p. 132-136.

74 F. Hartog, Régimes d'historicité. Présentisme et expériences du temps (La librairie du XXI ${ }^{e}$ siècle), Seuil, 2003, p. 61 ; H. Arendt, La crise et la culture. Huit exercices de pensée politique, P. Lévy (trad.), Gallimard, 1972, p. 63 : « La scène où Ulysse écoute l'histoire de sa propre vie est paradigmatique à la fois pour l'histoire et pour la poésie; la 'réconciliation avec la réalité', la catharsis, qui, selon Aristote, était l'essence de la tragédie, et selon Hegel, le but ultime de l'histoire, se produisait grâce aux larmes du souvenir. Le plus profond motif humain de l'histoire et de la poésie apparaît ici avec une pureté incomparable [...] puisque l'auditeur, l'acteur et celui qui souffre sont une seule et même personne ». 
manière « trop parfaite » le sort des Grecs ${ }^{75}$. Ulysse devient alors le témoin qui se lève et raconte autrement, face au poète qui chante. Larbitrage - tâche de l' Istôr - peut commencer : «La présence d'Ulysse, là-bas (à Troie) et ici (au banquet), fait attester que ça a réellement eu lieu. Se dessine là une configuration jusqu'alors inédite, une 'anomalie', puisque dans l'épopée la véracité de la parole de l'aède dépend tout entière de l'autorité de la Muse $\gg^{76}$.

Adhérant absolument aux relectures de cette scène fondatrice par Arendt et Hartog, j'ai poursuivi - modestement - la tâche en y ajoutant notamment deux éléments ${ }^{77}$ qui aujourd'hui permettent de lire la scène en fonction de la culture digitale. Premièrement, la rencontre entre l'aède qui chante le sort des Grecs et Ulysse le témoin n'aurait pas eu lieu sans ce que j’ai nommé la « part d'Athéna ", car c'est en effet la déesse qui va se soucier de susciter le retour d'Ulysse (Odyssée 6, 1-10). Ce rôle de la déesse dans l'épopée, je disais en 2010 que le hasard en était «la traduction moderne désenchantée ${ }^{78}$. Au sein de la culture digitale, nous pourrions nommer cette part d'Athéna plutôt « sérendipité », selon le terme consacré pour dire ce qu'on trouve sans l'avoir cherché, et qui a fait florès dans le monde numérique. Créée au $18^{\mathrm{e}}$ siècle par Horace Walpole à partir du conte oriental Les princes de Sérendip ${ }^{79}$, la sérendipité signifie « l'advenue et le développement d'événements par hasard, d'une manière heureuse ou bénéfique ${ }^{80}$. Cette définition correspond assez bien à l'expérience en ligne quotidienne du chercheur, qui ne cesse de trouver ce qu'il ne cherchait pas. Un accord tacite général semble se faire pour adjoindre la « sérendipité » au monde de l'écriture digitale open-ended, flexible, dynamique, toujours en évolution. Reste à savoir jusqu'à quel point les innombrables trouvailles en ligne sont heureuses.

C'est ce type de doute qui pousse probablement Michael Nielsen, dans son ouvrage Reinventing Discovery $(2012)^{81}$, à requalifier la sérendipité comme designed serendipity, lui accolant ainsi un parfum de téléologie utilitaire. S'il reconnaît la sérendipité comme une notion intermédiaire entre chance et

\footnotetext{
75 Homère, Odyssée 8, 487-491.

76 Hartog, Régimes d'historicité, p. 61.

77 Clivaz, L'ange et la sueur de sang, p. 136-142.

78 Clivaz, L'ange et la sueur de sang, p. 142.

79 Pour les textes de base concernés et une présentation de la notion, voir A. Volphillac D. Goy-Blanquet - M.-A. Paveau (éd.), Louis de Mailly. Les aventures des trois princes de Sérendip. Suivi de Voyage en sérendipité, Thierry Marchaisse éd., 2011.

80 Voir l'article «serendipity» dans English Oxford Living Dictionaries, <http://oxforddic tionaries.com/definition/english/serendipity .

81 M. Nielsen, Reinventing Discovery: the New Era of Networked Science, Princeton University Press, 2012.
} 
volonté, coïncidence et dessein, il considère que toutes les micro-collaborations provoquées par internet illustrent une designed serendipty: "Au lieu d'être une coïncidence occasionnelle de fortune, la sérendipité devient un lieu commun. La collaboration conduit à une sorte de designed serendipity ${ }^{82}$. Dans cette «part d'Athéna » numérique, c'est la foi en l'intelligence collective qui a remplacé l'intervention de la déesse, pour peu qu'on adhère à l'idée de la designed serendipity. Il y a en effet un curseur entre sérendipité et designed serendipity que nous déplaçons en fonction de notre appréciation du soi-disant bonheur sérendipitaire, comme nous y réfléchirons au point suivant.

Le second développement que j'ajoute à la relecture du face-à-face entre Ulysse et Démodocos est la dimension du politique, représentée par le roi Alcinoos dans la scène fondatrice. En effet, pour qu'Ulysse parvienne vraiment jusqu'à la prise de parole du témoin, il faut encore une dernière étape : faire taire celui qui a le pouvoir de la parole, Démodocos. Si Ulysse avait brièvement interrompu l'aède dans la scène mise en évidence par Arendt et Hartog, ce n'est qu'une quarantaine de vers plus loin qu'advient le dénouement de ce face-àface. C'est Alcinoos - autrement dit le pouvoir politique - qui demande à Démodocos de se taire pour écouter le témoignage d'Ulysse (Odyssée 8, 535-549): le pôle institutionnel, le pôle du pouvoir, se pose ici comme garant de l'expression du point de vue du témoin qui pleure par-delà celui du poète qui parle. Ce n'est toutefois pas par empathie ou compassion qu'Alcinoos intervient: le roi est plutôt « dérangé » par les larmes d'Ulysse, et le politique agit dans l'espoir d'un retour à une situation stable. Nul ne sait s'il va en résulter une «mémoire heureuse » de son intervention aux racines ambiguës, mais indispensable tout de même ${ }^{83}$. Il est urgent, me semble-t-il, que nous prêtions attention à cette intervention ambiguë et nécessaire d'Alcinoos dans le processus de prise de parole des « je » d'auteurs, historiens ou poètes, témoins ou aèdes. Alors que le discours historien avait mis tant de décennies à affronter le retour de l'émotionnel en son sein, comme chez Ankersmit et Ricœur, que ce soit pour les larmes ou l'apaisement, la culture digitale a précipité les «je » d'auteurs dans une exposition médiatique et immédiate sans précédent. On en prendra pour exemple une brève vidéo de l'historienne d'Harvard Karen King ${ }^{84}$, concernant

$82 \quad$ Nielsen, Reinventing Discovery, p. 27 ; voir aussi p. 251, note 228, où Nielsen explique qu'il emprunte le concept de designed serendipity à Jon Udell, «Sam's encounter with manifactured serendipity », Jon Udell's Radio blog, 4 mars 2002, <http://radio-weblogs.com/ 0100887/2002/03/04.html>.

83 Voir pour le développement complet Clivaz, L'ange et la sueur de sang, p. 140-141.

84 K. King, « Jesus said to them 'My wife...'. A New Coptic Papyrus Fragment », HTR 107 (2014/2), p. 131-159. 
un manuscrit chrétien antique à l'authenticité disputée, une vidéo d'abord mise en ligne puis retirée d'une page web de la Harvard Divinity School, mais encore accessible sur YouTube ${ }^{85}$, ainsi que toute la polémique qui en a résulté, avec riposte par vidéos ${ }^{86}$ et par articles ${ }^{87}$.

La rhétorique, avec son pouvoir à double tranchant, s'empare désormais chaque jour davantage des dires historiques en ligne, et nous voici incertains devant les fake news de tous bords. Qu'il agisse par agacement ou clairvoyance, Alcinoos, soit le pouvoir politique et institutionnel qui pondère et arbitre, est en passe de devenir l'acteur clé dont nous avons besoin dans la culture digitale. C'est ce qui explique sans doute la vivacité, voire l'âpreté, du débat politique que la Suisse a connu entre octobre 2017 et début mars 2018 quant au vote sur une initiative populaire qui visait ni plus ni moins à retirer tout subventionnement étatique à l'information publique, ce qui aurait été une première en Europe. L'initiative a finalement été rejetée à $71,6 \% 88$, et aura été l'occasion, pour ce petit pays à la démocratie vigoureuse, de redire clairement l'importance d'un lieu de parole publique qui tranche, bon an mal an, dans le flot des discours d'information. La Suisse a réaffirmé la nécessité d'Alcinoos.

En effet, Démodocos peut bien chanter, Ulysse peut bien pleurer puis raconter, tous les discours se mêlent et se fondent en d'étranges continua si aucun choix ne s'opère. Alors qu'Ankersmit et Ricœur concevaient encore ce choix comme reposant essentiellement sur la puissance du « je » individuel de l'auteur (historien), la culture digitale le replace pour partie du moins dans la responsabilité publique et collective des mains d'Alcinoos, car nos «je »

85 K. King, « 'Jesus said to them 'my wife” », vidéo publiée le 18 septembre 2012 par la Harvard Divinity School, puis retirée du site: <https://hds.harvard.edu/news/2012/og/18/ hds-scholar-announces-existence-new-early-christian-gospel-egypt\#>; accessible sur Youtube, <https://www.youtube.com/watch?v=vlmoILJmH4M>. La page web consacrée actuellement au sujet par la Harvard Divinity School présente sobrement le matériel produit par les chercheurs commandités par l'institution : <https://gospelofjesusswife. hds.harvard.edu/>.

86 S. Gathercole, « The Gospel of Jesus' Wife, interview with Dr Simon Gathercole », Cambridge University Press, 23 juin 2015, <https://www.youtube.com/watch?v=y-DBqoWo $\mathrm{Q}_{7} \mathrm{U}>$. La concurrence habituelle entre les universités de Harvard (USA) et Cambridge (UK) se fait ici par vidéos interposées.

87 La revue de référence New Testament Studies a consacré en juillet 2015 un numéro entier à la réfutation de l'authenticité de ce manuscrit (NTS 61 (2015/3), « Assessing the 'Jesus' Wife' Papyrus », p. 292-394, <https://www.cambridge.org/core/journals/new-testamentstudies/issue/AoFE2F1D7Fo946B325Co86B4BB4371Fo $>$ ).

88 Voir le blog d'annonce du résultat de la Radio Télévision Suisse (RTS), «L'initiative No Billag est rejetée par 71,6\% des votants et tous les cantons », RTs blog, 4 mars 2018, $<$ https://www.rts.ch/info/suisse/9369452-l-initiative-no-billag-est-rejetee-par-71-6-desvotants-et-tous-les-cantons.html>. 
d'auteurs, historiens, écrivains, simple quidam ou auteur académique, y sont devenus terriblement poreux, collectivisés, et à la merci de la gouvernance algorithmique. Voyons cela avec les voix d'une écrivaine, Annie Ernaux, et d'une juriste, Antoinette Rouvroy.

\subsection{Porosité, collectivité et (im-)puissance du «je » d'auteur dans la culture digitale}

Comme nous l'avons vu en 3.1 avec Ankersmit et Ricœur, la mémoire de l'historien est (re)devenue capable d'empathie, voire de sympathie avec le sujet qu'elle présente. Ankersmit dirait même qu'elle le doit, jusqu'à se faire «désordre mental à propos duquel nous pourrions ne jamais cesser de souffrir ${ }^{89}$. Cette nouvelle porosité du «je » de l'historien - ici sur le plan du pathos connaît un phénomène parallèle pour ce qui concerne le «je» de l'auteur littéraire, appelé à devenir une instance de plus en plus collective. Une représentation récente et maximale de ce phénomène serait l'innovant collectif de jeunes auteurs, l'AJAR, ancré en Suisse romande et formé d'une vingtaine de membres rédigeant romans et textes ${ }^{90}$, et qui mène son expérience dans un joyeux esprit de provocation ${ }^{91}$. Le phénomène du « je » d'auteur collectif incarné parl'AJAR - qui toutefois « ne croit absolument pas à l'idée de collectif » ${ }^{92}$ - peut faire écho à l'expérience d'écriture collective que nombre de chercheurs en Digital Humanities ont appris à vivre dans les inévitables Google docs ${ }^{93}$, ou leur version en licence libre les Framapad ${ }^{94}$, ces documents de travail rédigés à plusieurs où vos idées s'immergent dans celles des autres. Les modalités physiques de l'écriture digitale accélèrent la porosité $\mathrm{du}$ « je » d'auteur, alors que la

89 Ankersmit, Historical Representation, p. 193 ; cité ci-dessus, p. 109.

90 Voir notamment AJAR, Vivre près des tilleuls, Flammarion, 2016. Toute leur bibliographie se trouve sur <http://www.collectif-ajar.com>. Voir aussi cet article-vidéo : A. Bertina F. Bon, « Mais comment diable s'y prennent-ils ? Face à face entre deux écrivains (vidéo) », Cahiers d'Agora: revue en humanités 1 (2018), <https://www.u-cergy.fr/fr/laboratoires/ agora/cahiers-d-agora/numero-1/mais-comment-diable-s-y-prennent-ils-face-a-face-en tre-les-deux-ecrivains.html >.

91 AJAR, «L'AJAR c'est quoi?», bilingue, Das Narr. Das narrativistische Literaturmagazin 22 (2017), p. 142-147, <http://www.collectif-ajar.com/wp-content/uploads/2018/o1/AJAR_ Narr-21.pdf> ; ici p. 144: «L'AJAR pense que tout a déjà été dit. Du coup elle n'a aucune raison d'avoir peur. L'AJAR pense que les dictionnaires sont révolus. C'est pourquoi, si vous trouverez [sic] des fautes, ne nous en notifié [sic] pas. L'AJAR produit des textes, mais pas de para-métatextes. L'AJAR n'a jamais inventé personne. Et personne ne l'a jamais inventée. L'AJAR est presque sûre d'être immortelle. L'AJAR ne croit absolument pas à l'idée de collectif ; elle en est un par pure provocation ».

92 Voir la note précédente.

93 <https://www.google.com/docs/about/>.

$94<$ https://framapad.org/>. 
modernité, s'appuyant sur la culture imprimée et le romantisme, nous avait si bien fait croire au génie unique et solitaire.

En effet, la perception du « je » de l'auteur littéraire, tel un héros isolé dans la tour d'ivoire de l'inspiration, aura été une représentation qui a marqué jusqu'aux perceptions modernes des auteurs antiques. Revenant sur cet héritage romantique, le théologien Andreas Dettwiler souligne que l'exégèse paulinienne n'est plus à l'heure de l'image du « génie solitaire » ${ }^{95}$. Mais ce type de lecture a la vie dure, et en prendre la mesure nous aide ici à comprendre ce que la modernité - s'appuyant sur le cadre de la culture imprimée - a fait à la notion du « je » d'auteur. Dans son ouvrage qui analyse les interactions entre philosophie, exégèse du Nouveau Testament et sécularisation, Ward Blanton a fort bien démontré que l'image romantique de l'auteur a guidé au 19e siècle l'exégèse paulinienne d'Alfred Deissmann à l'orée du zoe siècle, notamment dans son ouvrage Licht von Osten (1923), où orientalisme et romantisme exaltent le « je » d'auteur de Paul ${ }^{96}$.

Ce sont les travaux de Deissman qui inspireront plus tard à Heidegger la fameuse expression de «l'esprit paulinien », exaltant l'auctorialité de l'apôtre, une perspective qu'on trouve ensuite reprise par le philosophe Alain Badiou: «Paul ordonne une critique anticipée de ce que Heidegger nomme l'ontothéologie, où Dieu se pense comme étant suprême, et donc comme mesure de ce dont l'être comme tel est capable ${ }^{97}$. Le poids d'une telle trajectoire théologico-philosophique sur la perception d'un auteur antique ne peut être sous-estimée, à lire d'autres passages de Badiou. Considéré comme un posttheological thinker ${ }^{98}$, il n'en arrive pas moins à considérer que

le geste inouï de Paul est de soustraire la vérité à l'emprise communautaire, qu'il s'agisse d'un peuple, d'une cité, d'un empire, d'un territoire, ou

95 A. Dettwiler, «L'école paulinienne: Evaluation d'une hypothèse », dans A. Dettwiler J.-D. Kaestli - D. Marguerat (éd.), Paul, une théologie en construction (Le Monde de la Bible 51), Labor et Fides, 2004, p. 419-440 ; ici p. 429. Pour un développement de la problématique, voir C. Clivaz, « La rumeur, une catégorie pour articuler autoportraits et réceptions de Paul. 'Car ses lettres, dit-on, ont du poids... et sa parole est nulle' (2 Co 10, 10)», dans Reception of Paulinism in Acts / Réception du paulinisme dans les Actes des apôtres (BETL 229), D. Marguerat (éd.), Peeters, 2009, p. 239-259.

96 W. Blanton, Displacing Christian Origins: Philosophy, Secularity, and the New Testament, University of Chicago Press, 2007, p. 112-122 ; A. Deissmann, Licht vom Osten: Das Neue Testament und die neuentdeckten Texte der hellenistisch-römischen Welt, Tübingen, Mohr \& Siebeck, 1923 .

97 A. Badiou, Saint Paul: la fondation de l'universalisme, PUF, 1998, p. 50.

98 Voir C. Watkin, Difficult Atheism : Post-Theological Thinking in Alain Badiou, Jean-Luc Nancy and Quentin Meillassoux, Edinburgh University Press, 2011, notamment p. 13. 
d'une classe sociale. Ce qui est vrai (ou juste, c'est en l'occurrence la même chose) ne se laisse renvoyer à aucun ensemble objectif, ni selon sa cause, ni selon sa destination. On objectera que «vérité » désigne ici, pour nous, une simple fable. C'est exact, mais ce qui importe est le geste subjectif saisi dans sa puissance fondatrice quant aux conditions génériques de l'universalité ${ }^{99}$.

De par l'ampleur et la durée de sa réception, le cas de Paul de Tarse est particulier pour l'étude de l'auctorialité antique, mais elle met au moins en évidence on ne peut plus clairement l'effet de la conception moderne et romantique de l'auteur : ce qui est indiqué ici par Badiou comme un processus d'universalisation de l'auctorialité paulinienne tient presque entièrement au postulat implicite du génie solitaire de l'auteur, où agit de manière quasi autonome un « esprit paulinien ». Dans son ouvrage, Blanton démonte patiemment un tel point de vue, en soulignant notamment la présence discrète mais ferme de Tertius en Rm 16, 22, secrétaire et écrivain au sens littéral du terme de l'Epître aux Romains ${ }^{100}$. Pour ma part, je relèverai ici que, de manière parallèle à ce qui est advenu au «je » de l'historien, on assiste désormais à une refonte complète d'une telle conception du « je » d'auteur littéraire, ici biblique.

La culture du livre, s'appuyant sur l'assurance juridique d'un texte fixé - figé, faut-il dire «momifié » ? - et sur le droit implacable de l'auteur à se voir respecter ${ }^{101}$, avait bâti la tour d'ivoire de l'auteur génie solitaire, pouvant prétendre à l'universalité de son point de vue, historique ou littéraire. C'est à tout autre chose que conduit l'élaboration par Annie Ernaux d'un « je » singulier qui tend au collectif, notamment dans son ouvrage Les Années $(2008)^{102}$. Depuis mon premier article d'importance sur la culture digitale ${ }^{103}$, cette autobiographie culturelle d'Annie Ernaux accompagne ma réflexion, car on y perçoit assez exactement la présence d'abord sourde, puis plus forte, du numérique, comme à la fois sans réelle importance, mais modifiant inexorablement le décor. On y trouve entre autres un passage que je continue à considérer comme

\footnotetext{
99 Badiou, Saint-Paul, p. 6.

100 Blanton, Displacing Christian Origins, p. 127: « The place of (a) Tertius in the biblical legacy remains to be fixed [...], and promises a return on an investment in the further analysis of the ancient (and modern) intertwining of religion and writing technologies of all sorts ».

101 Voir sur ce thème E. Neeman - J. Meizoz - C. Clivaz, « Culture numérique et auctorialité : réflexions sur un bouleversement », A Contrario 17 (2012), p. 9-41; part. p. 19-21.

102 A. Ernaux, Les Années, Gallimard, 2008.

103 Clivaz, Common Era, p. 24.
} 
saisissant avec une acuité sans pareille ce que nous fait l'irruption de l'ère digitale :

Dans le brassage des concepts, il était de plus en plus difficile de trouver une phrase pour soi, la phrase qui, quand on se la dit en silence, aide à vivre. Sur Internet il suffisait d'inscrire un mot clé pour voir déferler des milliers de « sites », livrant en désordre des bouts de phrases et des bribes de textes qui nous aspiraient vers d'autres dans un jeu de piste excitant, une trouvaille relancée à l'infini de ce qu'on ne cherchait pas. Il semblait qu'on pouvait s'emparer de la totalité des connaissances, entrer dans la multiplicité des points de vue jetés sur les blogs dans une langue neuve et brutale $^{104}$.

En quelques mots, voici la sérendipité évoquée par cette « trouvaille relancée à l'infini de ce qu'on ne cherchait pas », ainsi que l'abysse du lieu digital désigné par les «sites » qu'Ernaux met entre guillemets. Ce passage met en scène le Vertige de la liste ${ }^{105}$ via le déferlement des "phrases et des bribes de textes » dans le «jeu de piste excitant». En quelques mots, Ernaux prend ensemble le rêve fantasmatique de la bibliothèque d'Alexandrie définitive et la brutalité de cette novalangue de l'internet, alors qu'on ne peut plus trouver dans ce bric-àbrac foutraque une «phrase pour soi », qui « aide à vivre », à se dire « en silence ». Alors qu'arrive cette vague digitale, Annie Ernaux cherche à mettre en œuvre dans Les Années un «je » à la fois individuel et collectif, comme elle l'explique dans un texte préparatoire publié sur le site Libr-critique :

«Elle est née à L. en 1940 ». (Commencer ainsi suppose qu'il est possible de transformer en histoire l'existence, vague et sans signification à ses propres yeux, d'une femme qui a vécu de la dernière guerre à aujourd'hui - où elle vient de voir à la télé, comme la plupart des Européens et des Américains, le procès de Nicolae et d'Elena Ceausescu avant leur exécution. Cela veut dire, non pas glisser cette existence dans une forme romanesque, que les modèles en soient ceux de La Recherche du Temps perdu ou d'Autant en emporte le vent, mais de chercher à en atteindre la réalité, à la fois singulière et partagée peut-être par une génération. Prendre en compte ses désirs, ses expériences personnelles, moins uniques qu'elle ne l'a cru longtemps, et la série des déplacements, des influences - milieux, idées - grâce auxquelles elle s'est constituée. Décrire ce qui a 
changé autour de cette femme et en elle. Bref, rester toujours à la croisée de sa mémoire et de l'Histoire, de l'individuel et du collectif, en utilisant la troisième personne, le « elle », qui, dans certains cas, n'est que la forme historique, objective et distanciée d'un « je » $)^{106}$.

Et encore : «Ce 'je' que j'emploie encore ici ne m'appartient pas complètement, il est un lieu de pensées, de désirs, que j'ai dû partager avec autrui. Je ne suis, d'une certaine façon, que du temps qui a passé à travers moi » ${ }^{107}$.

Ce «je », collectif et poreux, est donc un « lieu de pensées, de désirs, que j’ai dû partager avec autrui », qui dit une histoire tout à fait singulière mais « partagée peut-être par une génération », et qui n'est plus de forme romanesque mais « veut rester toujours à la croisée de sa mémoire et de l'Histoire, de l'individuel et du collectif ». Cette recherche d'ordre littéraire, mais qui s'appuie sur quelques photographies dans Les Années, se retrouve explorée, testée et mise en scène dans de nouvelles formes de mémoire collective rendues possibles par la culture digitale. On en prendra pour exemple le projet roumain $A$ collective memory 1950-2000, qui se présente comme une grande collection d'archives privées des individus, mais dans le but de créer une mémoire collective: «Cette archive est plus que la simple juxtaposition d'images et de leurs récits dans un grand et nostalgique album de Roumanie. Notre but est de récupérer, rassembler et mettre à disposition un nombre considérable d'images, et d'en faire usage de sorte à atteindre le poids mémoriel de l'archive, et offrir ainsi des ressources pour de futures études culturo-anthropologiques, artistiques, historiques et sociologiques ${ }^{108}$. On pourrait dire que ce projet roumain tente à large échelle, et via les images, de collecter Les Années de centaines d'individus, rendant ainsi matériellement visible «ce 'je' [qui] ne m'appartient pas complètement», qui n'est «d'une certaine façon, que du temps qui a passé à travers moi », pour reprendre les mots d'Ernaux.

Si une telle conception du « je » auctorial de l'écrivain/e n'est pas née au creuset de la culture digitale, cette culture est certainement un puissant accélérateur pour la pratique et l'émergence d'un tel «je ». Notamment, l'émergence

106 Libr-critique. La littérature dans toutes ses formes, « [Dossier Annie Ernaux -3] Annie Ernaux, cinq avant-textes des Années », 23 septembre 2011, <http://www.t-pas-net.com/librcritique/dossier-annie-ernaux-3-annie-ernaux-cinq-avant-textes-des-annees/>. Ibid.

108 A collective memory 1950-200o, <http://www.memoriecolectiva.org/>. Voir C. Clivaz, « La mémoire et les maux. Collecter les individus », Blog Le Temps 8 décembre 2017, <https:// blogs.letemps.ch/claire-clivaz/2017/12/08/la-memoire-et-les-maux-collecter-les-indivi dus/>. 
d'objets digitaux multimodaux, mariant texte, images et sons, augmente sans cesse notre familiarité avec la porosité $d u$ «je ». On pourra prendre pour exemple cette vidéo YouTube d'une interview d'Emmanuelle Riva en 1959 sur son rôle dans Hiroshima, mon amour ${ }^{109}$. D'une manière imperceptible, mais emblématique et frappante, elle passe, d'une phrase à l'autre, de son « je » personnel à celui de l'héroïne qu'elle incarne dans le film. Voici le passage retranscrit : j'y indique en gras le «je » de transition vers son personnage :

$\mathrm{Au}$ théâtre, on m'a toujours donné les rôles de jeunes filles, les rôles d'ange, je crois, un peu. On ne voulait jamais me voir dans les infidèles. Mais cette fois, je suis vraiment une infidèle, enfin je suis une femme libre. [Silence] Dans ma prime jeunesse, j'ai connu un amour allemand sous l'occupation. Un grand amour, et je devais partir en Bavière. Mais il est mort. Et moi je ne suis pas morte d'amour.

L'oralité a toujours favorisé ce genre de transition, à la fois opaque et advenant en continu. Avec la multiplication en ligne des supports visuels, oraux, multimodaux, ainsi que des niveaux de formes, de genres et de discours, nous sommes désormais constamment mis face à des porosités de « je » d'individus et d'histoires collectives. Désormais la dernière manifestation se suit sur un smartphone privé, le journaliste se bat pour garder un territoire, et la voix d'auteur semble pouvoir se confondre avec celle du quidam. Aucune surprise donc à voir se produire des réactions au phénomène, par exemple via le nombre grandissant des performances littéraires de tous ordres ${ }^{110}$. Comme le souligne Jérôme Meizoz,

les prestations publiques demandées aux écrivains (lectures, séances de signature, entretiens) ou assurées par des collectifs (lectures avec musiciens, soirées slam) sont courantes, parties intégrantes de la circulation des textes. Au cours de ces activités, les auteurs incarnent leurs écrits, qu'il s'agisse de les promouvoir et/ou de les performer. Plusieurs termes ont été forgés ces dernières années, pour désigner ces phénomènes : on parle de « littérature exposée », de « littérature contextuelle » ou encore de « littérature hors du livre ». [...] Contemporaines de formes de « publicisation » du littéraire comme les festivals, lectures, ateliers et ballades,

109 «Emmanuelle Riva, interview 1959 », YouTube 16 septembre 2009, <https://www.youtube. com/watch?v=kRMadyuhos4>.

110 Voir par exemple J. Meizoz, La Littérature «en personne ». Scène médiatique et formes d'incarnation (Erudition), Slatkine, 2016. 
les formes et contextes de telles pratiques changent sous nos yeux, dans le sens d'une plus grande in-teractivité avec le public. A tel point que certains y voient le signe d'un «tournant festivalier » de la vie littéraire ${ }^{111}$.

Ces diverses formes de mise en scène permettent au «je » des écrivains de regagner en visibilité et en résistance dans la marée des récits et des discours, alors que la couverture même du livre, comme signe de reconnaissance, voire de diagnostic, est mise à mal par la flexibilité de l'écriture en ligne ${ }^{112}$. La résistance des «je» d'auteur essaie de s'organiser, alors que l'heure ne peut être qu'à la lucidité : nous faisons l'expérience quotidienne, à une vitesse exponentielle, de la porosité et la collectivisation de nos « je », qu'ils soient d'auteurs, d'historiens, de journalistes, de simple quidam, et ce dans la plus grande contradiction qui soit. En effet, alors même que nous sommes immergés dans le plus joyeux mélange des discours en ligne, la moindre de nos traces électroniques pourrait, à moins de précautions, nous être rapportée via l'adresse IP du média électronique que nous utilisons. In fine, et ce sans même que nous l'ayons consciemment et collectivement décidé un jour, la gestion de nos données - de ce que littéralement nous livrons et donnons à l'internet - atterrit dans les mains de ce nouvel Alcinoos qu'est la gouvernance politique et économique des données ${ }^{113}$.

Et ce dans le meilleur des cas s'entend, car à lire un article d'un chercheur de l'Ecole Fédérale Polytechnique de Zurich, Marco Ienca, d'aucuns postulent déjà le phénomène du brainjacking, lorsqu'un hacker s'en prendra à l'implant greffé dans un cerveau pour en trafiquer les données ${ }^{114}$ ! La police neuronale est quant à elle déjà entrée en action avec ce cas d'école en Inde en 2008 : une femme a été condamnée à l'emprisonnement à vie sur la base du scan de son cerveau qui, selon le juge, démontrait une « connaissance expérimentale » du crime $^{115}$. Chaque corps de métier cherche déjà à recomposer sa place dans ce

111 J. Meizoz, « 'Écrire, c'est entrer en scène' : la littérature en personne », CONTEXTEs, Varia, mis en ligne le 10 février 2015, §1-35, <http://journals.openedition.org/contextes/6003> ; ici $\$ 13$ et 15 .

112 Voir le point 4.1 de ce chapitre.

113 Voir le point 3.1 de ce chapitre.

114 M. Ienca, « Preserving the Right to Cognitive Liberty. A new type of brain-imaging technology could expose - even change - our private thoughts », Scientific American 1er août 2017, <https://www.scientificamerican.com/article/preserving-the-right-to-cog nitive-liberty/>.

115 Ienca, « Preserving the Right to Cognitive Liberty », <https://www.scientificamerican. com/article/preserving-the-right-to-cognitive-liberty/>. 
nouvel agencement : des avocats planchent sur le droit à la liberté cognitive, explique Marcello Ienca ${ }^{116}$.

Ce qui nous paraît toujours un peu irréel quand cela se passe ailleurs et nous est relaté en anglais, devient brusquement concret et se présente à portée de main lorsqu'un article de l'excellent média [Analyse Opinion Critique] rapporte le dernier discours du président Emmanuel Macron sur l'Intelligence Artificielle. Il est rapporté et commenté sous la plume du chercheur en informatique Jean-Gabriel Ganascia. Le verdict semble on ne peut plus clair :

Le principe selon lequel chacun sera en mesure de maitriser ses données personnelles semble antinomique avec la nature même de l'information que l'on duplique à loisir, sans aucun coût, et que l'on transmet à l'insu de tous, en particulier de celui qui est censé en être le propriétaire. Jusqu'à quel point peut-on surmonter cette antinomie ? Cela conduit à se demander si l'Europe aura vraiment la possibilité de réguler, par la seule force du droit, les données des citoyens européens et si les États européens parviendront effectivement à affirmer leur souveraineté sur le monde numérique, en s'opposant aux grands acteurs internationaux qui disposent de moyens financiers considérables et font de l'entrisme jusque dans les institutions européennes ${ }^{117}$.

Alcinoos n'aura-t-il d'autre choix que de se faire Pilate, de s'en laver finalement les mains et de prendre soin de se dédouaner à l'avance des conséquences fâcheuses pour les individus du gouvernement algorithmique ? Nos « je » deviendront-ils poreux au point de livrer toutes nos données ? Et oui, et Alcinoos n'y pourra pas grand'chose, semble répondre Ganascia transcrivant le propos présidentiel. En revanche, Emmanuel Macron s'est enflammé à considérer les possibles d'une gouvernance algorithmique :

Le Président, qui demeure avant tout un philosophe, ancre le projet de l'intelligence artificielle, né, comme il l'a rappelé, au milieu du xx siècle, dans une perspective plus vaste, ouverte il y a plusieurs siècles par Leibniz, selon qui Dieu opère partout par calcul. Désormais, les machines contemporaines aidant l'Homme à agir par calcul, elles le rapprochent

116 Ienca, «Preserving the Right to Cognitive Liberty », <https://www.scientificamerican. com/article/preserving-the-right-to-cognitive-liberty/>.

117 J.- G. Ganascia, «IA, les enjeux d'un changement de société », [Analyse Opinion Critique], 3 avril 2018, <https://aoc.media/analyse/2018/04/o3/intelligence-articificielle-enjeuxdun-changement-de-societe/>. 
un peu du Dieu. Il y a là une forme de transgression et quelque chose de prométhéen! 118

On est bien sûr frappé de voir encore une fois une comparaison religieuse évoquée ici, assumant jusqu'à la part fantasmatique de toute-puissance. Mais via son côté transparent et univoque, elle a le grand mérite d'illustrer parfaitement l'analyse d'une justesse implacable faite de la question par la docteure en droit Antoinette Rouvroy ${ }^{119}$ :

La cible ou le «projet » de la gouvernementalité algorithmique ne serait plus, comme dans le biopouvoir décrit par Foucault, la folie, la maladie, le crime, la déviance, les enfants ou les pauvres, mais plutôt ce qui, des comportements possibles des personnes, échapperait au calcul et à l'optimisation, c'est-à-dire leur « puissance ». On peut définir cette « puissance » comme ce dont ils sont capables mais dont on ne peut à aucun moment être assuré, c'est-à-dire leur capacité à ne pas être là où ils sont attendus, en somme : leur non-cö̈ncidence avec tout «profilage», toute «prédiction ». De cette puissance des sujets, dirons-nous, il ne peut être rendu compte par des chiffres, par des données, mais seulement par des mots et toujours dans l'après-coup, sur le mode de la fabrication singulière, ou de la «comédie », ou encore de la rationalisation contrefactuelle, à contretemps, par laquelle les personnes, aussi déterminées et peu libres aient-elles été dans leurs choix et leurs actes, se rendent néanmoins « dignes de ce qui leur arrive $»^{120}$.

L'analyse de Rouvroy est parfaitement illustrée par la perspective du président Macron : c'est bien à la prédiction des comportements que l'Etat s'intéresse via l'IA et la gouvernance algorithmique, « les machines contemporaines aidant l'Homme à agir par calcul », comme l'écrit Ganascia. Comment vont réagir les « je » d'auteurs à moyen terme devant les freins mis à leur « puissance», alors même que la culture moderne et imprimée avait exalté leur autonomie de génie solitaire? «Je» d'auteur et «je » de quidam, allons-nous nous laisser

118 Ganascia, «IA, les enjeux d'un changement de société », <https://aoc.media/analyse/2018/04/03/intelligence-articificielle-enjeux-dun-changement-de-societe/>.

119 Antoinette Rouvroy, « docteur en sciences juridiques de l'Institut universitaire européen (Florence, 2006), est chercheuse qualifiée du FNRS au centre de Recherche en Information, droit et Société (CRIDS). Elle s'intéresse depuis 2000, aux rapports entre le droit, les modes de construction et de [gestion] du risque, les sciences et technologies, et la gouvernementalité néolibérale » (https://directory.unamur.be/staff/arouvroy).

Rouvroy, « La vie n'est pas donnée », p. 198. 
défaire de notre puissance, ou au contraire nous convaincre qu'il nous reste une possible «non-coïncidence avec tout 'profilage', toute 'prédiction' » ? Et si nous arrivons un tant soit peu à cette conviction, faut-il alors, comme Rouvroy semble le faire, jouer l'alternative des mots contre les chiffres?

Partageant absolument avec Antoinette Rouvroy l'analyse que c'est bien après notre puissance de sujets, même poreux et collectivisés, qu'en a la gouvernance algorithmique, je propose de conclure la réflexion de ce point 3 par un appel au for intérieur, dans ce qu'il a de conscient et non conscient, de pensé et d'impensé : c'est un chemin possible pour prendre ensemble les chiffres et les mots et rassembler ce qui reste des débris épars de la puissance du sujet. Nathalie Sarraute, en précurseur, nous a offert de quoi nourrir et préparer cette résistance des sujets à maintenir dans leur for intérieur quelque chose de leur puissance, « aussi déterminés et peu libres » soient-ils.

\subsection{En quête du for intérieur avec Nathalie Sarraute}

Comme nous l'avons vu au chapitre 2, c'est dès Tropismes (1939) que Nathalie Sarraute met en scène littéraire le jeu entre perceptions conscientes et non conscientes, usant d'un terme de biologie végétale. Elle analyse ensuite ce trait littéraire en 1956 au début de l'Ere du soupçon ${ }^{121}$. Cet impensé ou unthought a souvent été évoqué de manière poétique (voir l'exemple de Wordsworth ${ }^{122}$ ) ou mystique :Katherine Hayles le reprend de la tradition Zen en titre d'ouvrage ${ }^{123}$, alors que Paul de Tarse évoque en Rm 8, 26 les « soupirs inexprimables »- littéralement non parlés (alalètoï) - de l'esprit ${ }^{124}$. Quels que soient les registres associés à ce type de perceptions, leur trait commun est d'être considérés en deçà des mots, du côté du «non parlé », mais sans se situer pour autant du côté des chiffres : l'alternative campée par Rouvroy entre mots et chiffres ne tient pas toujours, à tout moment.

Cet impensé appartient de fait au for intérieur, cette « immense masse mouvante », « où l'on trouve tout ce qu'on veut », comme Nathalie Sarraute le décrit plus loin dans l'Ere du soupçon. Sa description du for intérieur, échappant à toute grille de lecture, y compris la psychanalyse, ne peut que frapper l'esprit du lecteur/lectrice par son aspect précurseur, au milieu des années cinquante :

On sait combien, dans notre hâte, dans la nécessité où nous sommes, à chaque instant, d'aller au plus pressé, de nous guider d'après les plus

\footnotetext{
121 Voir Sarraute, L'Ere du soupçon, p. 59; cité au chapitre 2, p. 79.

122 Voir Wordsworth, The Prelude, 138-140 ; cité au chapitre 2, p. 88-89.

123 Voir Hayles, Unthought, p. 1; cité au chapitre 2, p. 77-78.

124 Voir chapitre 2, p. 79.
} 
grossières apparences, nous pouvons être ignorants et crédules. Il suffit de se rappeler quelle révélation a été pour nous le monologue intérieur ; la méfiance avec laquelle nous avons considéré et considérons parfois encore les efforts de Henry James ou de Proust pour démonter les rouages délicats de nos mécanismes intérieurs ; avec quel empressement nous acceptons de croire que telle grille - comme la psychanalyse - posée sur cette immense masse mouvante qu'on nomme notre « for intérieur », où l'on peut trouver tout ce qu'on veut, la recouvre tout entière et rend compte de tous ses mouvements ; et avec quelle satisfaction, quel sentiment de délivrance nous nous sommes laissés convaincre, et sommes restés, pour la plupart d'entre nous, convaincus, que ce «for intérieur », tout récemment encore si fertile en découvertes, n'existait pas, n'était rien : du vide, du vent ${ }^{125}$.

Ce passage de l'Ere du soupçon est l'annonce par Sarraute de son attention constante au for intérieur, dont elle esquisse ici l'allure générale, qui va se «peupler et s'élargir» dans ses écrits suivants, comme l'indique Germaine Brée ${ }^{126}$. Celle-ci ajoute : « me permettant un jeu de mots auxquels m'autorisent de nombreuses images disséminées dans les textes de Sarraute, c'est aussi, pour elle, un 'fort', sans cesse menacé par des troupes hostiles, des 'émissaires' du 'for' public ${ }^{127}$. Brée nous rappelle aussi utilement l'origine étymologique $\mathrm{du}$ for public, le forum romain, auquel répondra le for intérieur, place de l'intime ${ }^{128}$. J'insisterai pour ma part sur ce pendant du for intérieur qu'est le for extérieur ou externe, soit « l'autorité de la justice humaine s'exerçant sur les personnes et sur les biens ${ }^{129}$. Cette définition nous ramène à la sphère de juridiction de la gouvernementalité algorithmique pointée par Rouvroy: a contrario ou par défaut, le for intérieur semble bien être, quant à lui, ce qui n'est pas soumis au for extérieur de cette gouvernementalité ; il peut donc se donner comme le lieu à cultiver pour développer la puissance du sujet malgré tout, et sa non-coïncidence aux prédictions faites sur les sujets.

Mais il n'est pas pour autant cartographiable, comme ont pu le penser certains lecteurs de Sarraute qui, à mon sens, rigidifient le for intérieur, veulent à tout prix le localiser, le repérer, l'enclore. C'est le cas de Monique Wittig qui

\footnotetext{
125 Sarraute, L'Ere du soupçon, p. 162-163.

126 G. Brée, « Le 'for intérieur' et la traversée du siècle », L'Esprit Créateur 36 (1996), p. 37-43 ; ici p. 37 .

127 Brée, «Le 'for intérieur' », p. 37.

128 Brée, «Le 'for intérieur' », p. 37.

129 Voir « For », Dictionnaire Larousse en ligne, <http://www.larousse.fr/dictionnaires/fran cais/for/34539>.
} 
comprend le «for intérieur » chez Sarraute comme un «théâtre total», un «théâtre mental où tout est permis » ${ }^{130}$. Mais de même que "Nathalie Sarraute [elle-même] échappe à toute classification littéraire, nationale ou sexuelle ${ }^{131}$, le « for intérieur » ne saurait être domestiqué et Sarraute ne peut répondre que par une pirouette à Wittig qui lui demande si le roman Ici ne se situe pas dans le for intérieur : «'Ici', on ne sait pas qu'on est dans le for intérieur. Ce qui apparaît occupe tout. Et quand cela apparaît, on établit des cloisons pour que cela occupe justement tout l'espace qu'on lui réserve ${ }^{132}$.

Germaine Brée a bien raison de garder fermement le lien du for intérieur à la sensation non parlée : « dès qu'elle est mise en mots, la sensation n'est plus ce qu'elle était ${ }^{133}$. C'est parce que le for intérieur est lié aux sensations, à l'unthought qu'il peut être un lieu de résistance à la prédiction algorithmique ; c'est parce qu'il est partiellement fait de ce qui vient avant les mots, mais n'est pas non plus chiffré, qu'il peut peut-être prétendre à préserver quelque chose de la puissance du sujet, même en régime culturel virtuel. Arnaud Claude esquisse en 2010 un lien entre le for intérieur de Sarraute et le monde virtuel : « Hasard ou nécessité, ce for d'origine latine qu'explore l'auteur de Tu ne t'aimes pas provient du même étymon que le forum où les Anciens disputaient des affaires de la cité. Il est l'agora virtuelle où s'expriment nos contradictions intimes » ${ }^{134}$.

De fait, le for intérieur de Sarraute - lieu a contrario fait de ce qui n'est pas sous le régime politique et juridique du for extérieur - a toutes les caractéristiques pour être un moteur de recouvrement de la puissance des sujets, y compris sa capacité à éliminer une conscience centrale, « remplacée par une foule de voix, toutes émanant d'un 'moi' qui est un 'nous' » ${ }^{135}$, comme Brée le résume, nous ramenant ici au « je » collectif mis en récit par Ernaux. Last but not least, Brée a l'intuition de lier « for intérieur » et «traversée du siècle » dans le titre de son article. Elle exploite peu dans la suite de son texte ce qui pourrait être la dimension politique ou de résistance au politique de la notion de for intérieur chez Sarraute. Il me paraît pourtant évident que, sans les conditions sociales et politiques de son parcours de vie ${ }^{136}$, Sarraute n'aurait pas prêté une telle attention à l'impensé et au for intérieur. Elle nous livre un chemin de ré-

\footnotetext{
130 M. Wittig, « Avatars », L'Esprit Créateur 36 (1996/2), p. 109-116 ; ici p. 114.

131 A. Claude, «Sarraute en son for intérieur », Le Magazine Littéraire 500 (2010/9), p. 71-71, <http://www.cairn.info/magazine-le-magazine-litteraire-2010-9-page-71.htm>. M. Wittig, « Le Déambulatoire. Entretien avec Nathalie Sarraute », L'Esprit Créateur 36 (1996/2), p. 5-8; ici p. 7-8.

133 Brée, « Le 'for intérieur' », p. 41.

134 Claude, «Sarraute en son for intérieur », p. 71.

135 Brée, « Le 'for intérieur' », p. 41.

136 Voir chapitre 2, p. 80.
} 
sistance - selon Claude, Sarraute se retrouvait dans cette sentence, the achievement is in the pursuit ${ }^{137}$ - dont l'aspect politique ne peut plus être minoré, comme il l'a souvent été dans des études proprement littéraires ou psychologisantes de Sarraute.

Les murs des prisons à venir seront faits sans doute en grande partie d'algorithmes et les «cyber attaques vont avoir des conséquences équivalentes à celles des guerres conventionnelles », prophétisait à fin 2017 Yves Daccord, directeur du comité général de la Croix-Rouge ${ }^{138}$. A l'échelle des individus, se déplacer avec un smartphone implique que nous pourrions être joignables en tous temps ${ }^{139}$. Telle est la vie où nous n'avons pas choisi d'entrer, mais à laquelle nous participons tous désormais inconsciemment de notre plein gré. Au mois de mars 2018, le parlement suisse a accepté les propositions d'assureurs privés pour surveiller les «mauvais » assurés, comme on peut le lire dans la presse :

Outre les enregistrements visuels et sonores, le projet permet des techniques de localisation de l'assuré, comme les traceurs GPs fixés sur une voiture. A la différence des enregistrements, l'autorisation d'un juge sera nécessaire dans ces cas. Des drones pourraient également être utilisés, à condition qu'ils servent à la géolocalisation et non à une observation. La surveillance ne sera pas limitée à l'espace public, comme les rues ou les parcs. Elle sera effectuée aussi dans des lieux visibles depuis un endroit librement accessible, par exemple un balcon ${ }^{140}$.

137 Claude, « Sarraute en son for intérieur », p. 71.

138 ATs, «Yves Daccord restera deux ans de plus à la tête du CICR », Le Temps 5 novembre 2017, <https://www.letemps.ch/suisse/yves-daccord-restera-deux-ans-plus-cicr >. Pour un avis différent, voire divergent, voir Tréguer, Pouvoir et résistance dans l'espace public, $<$ https://halshs.archives-ouvertes.fr/tel-01631122>, notamment p. 499-500.

139 Voir la page web des produits Apple « À propos des alertes d'urgence et du gouvernement sur l'iPhone et l'Apple Watch », <https://support.apple.com/fr-ch/HT202743>, mis à jour le 10 octobre 2018: «Activer ou désactiver les alertes du gouvernement: Par défaut, les alertes du gouvernement sont activées sur votre appareil. Lorsque vous recevez ce type d'alerte, vous entendez un son spécifique, similaire à celui d'une alarme. Pour activer ou désactiver ces alertes, procédez comme suit : Rendez-vous dans Réglages $>$ Notifications. Faites défiler jusqu'au bas de l'écran. Sous Alertes du gouvernement, activez ou désactivez les alertes».

$140 \mathrm{ATS} / \mathrm{NXP}$, « Surveiller les assurés? Un référendum est lance », Tribune de Genève 28.03.2018, $<$ https://www.tdg.ch/suisse/surveiller-assures-referendum-lance/story/31622337>. 
Le vote du parlement a mis en route un référendum, et le peuple suisse a finalement accepté le 25 novembre 2018 ces propositions ${ }^{141}$. Mais gardons-nous de penser que seules les collectivités auront le moyen de contraindre à la surveillance : le quidam y est désormais invité de lui-même. Lorsque nous aurons renoncé au carnet de papier recevant nos pensées intimes et que nous aurons installé dans nos maisons et voitures des assistants informatiques enregistrant nos propos, restera-t-il seulement encore une trace de notre for intérieur qui ne sera directement à disposition du for extérieur, étatique ou autre?

La question se pose d'autant plus que des chercheurs du MIT de Boston viennent d'annoncer la création d'un casque dénommé AlterEgo, un "décodeur de pensées », « un système portable qui permet à l'utilisateur de discuter silencieusement avec un ordinateur sans aucun usage de la voix, ni aucun mouvement discernable », comme l'indique la vidéo YouTube qui présent l'en$\operatorname{gin}^{142}$. A regarder ces images, on a d'un coup l'impression que Nathalie Sarraute s'est fait oracle au siècle dernier en décrivant dans Tropismes et l'Ere $d u$ Soupçon les «mouvements indéfinissables », « ces mouvements, aucun mot pas même les mots du monologue intérieur - ne les exprime, car ils se développent en nous et s'évanouissent avec une rapidité extrême, sans que nous percevions clairement ce qu'ils sont $»^{143}$. Faut-il voir dans ce type d'exploration technologique la possibilité de venir à bout jusques et y compris du for intérieur ? Le simple fait que la question soit posée devrait convier à bien réfléchir à tout ce qui pourrait nous conduire à vouloir un jour nous harnacher d'un $\mathrm{Al}$ terEgo.

Le « je » d'auteur, embarqué dans cette ambiance culturelle digitale et dans des processus qui le rendent chaque fois plus poreux et collectif, semble voué à constater la réduction drastique de sa puissance de sujet. Plongé dans cette langue d'internet «neuve et brutale » (Ernaux), le «je » d'auteur, du quidam à l'écrivain en passant par l'historien, apprend à articuler tant que faire se peut l'impensé, le for intérieur et le for extérieur. C'est ce à quoi nous aura conduit la «traversée du siècle » : sans consolidation et développement du for intérieur, sans une volonté claire de le garder non cartographiable dans son ensemble, fût-ce par la plus performante des psychanalyses associée à un scanner

141 Voir C. Clivaz, «Pourquoi restons-nous attachés aux sociétés de surveillance ? », Blog Le Temps, 9 juin 2018, <https://blogs.letemps.ch/claire-clivaz/2018/o6/og/pourquoi-aimonsnous-les-societes-de-surveillance/>; B. Wutrich, «Assurances sociales: le mythe du drone dans la chamber à coucher », Le Temps, 25 novembre 2018, <https://www.letemps. $\mathrm{ch} /$ suisse/assurances-sociales-mythe-drone-chambre-coucher $>$. avril 2018, <https://youtu.be/RuUSc53Xpeg>.

Sarraute, L'Ere du soupçon, p. 59 ; cité au chapitre 2, p. 79. 
du cerveau ou à la ribambelle des AlterEgo à venir, toute possibilité de résistance de la puissance du sujet s'évanouira. Désormais, celle ou celui qui se pique de vouloir écrire, quel que soit le genre littéraire visé ou le niveau d'écriture, devra apprendre à mesurer ce qu'il livre à l'internet pour que la vie ne soit pas donnée ${ }^{144}$ et que demeurent intacts au moins des fragments de for intérieur.

\section{L'appareillage du livre : ce qu'on quitte, ce qu'on transforme, ce qu'on acquiert}

Avant que nous ne soyons aux prises avec le brainjacking, voués à la puce électronique qui nous écrira à même la chair, ou avec le casque AlterEgo qui scrutera notre for intérieur, prenons le temps de tourner les regards vers le rivage qu'on quitte et d'observer ce qui a pris place dans le radeau de la Méduse numérique, et ce qui advient des points importants de la culture du livre, ces points de repère qui ont façonné notre manière de penser depuis des siècles. On considérera aussi ce qu'on acquiert dans ce voyage aventureux. Ce point fait le pari d'être synthétique afin d'offrir un aperçu de la question, chaque sujet pouvant faire l'objet d'une monographie à part entière. Il ne prétend donc pas à l'exhaustivité mais se veut survol d'un terrain complexe à décrire ${ }^{145}$.

J'ai choisi d'aborder ici les points qui se sont le plus immédiatement présentés à mon enquête au cours des dernières années. Un sujet d'importance sera différé au chapitre 4 , celui des corpus de textes ${ }^{146}$. En effet, le chapitre 4 se penchera sur les Ecritures chrétiennes, corpus textuel par excellence : j'y joindrai donc la réflexion sur le devenir de cette notion, et de sa notion corollaire ou opposée, le fragment, apparemment devenu roi dans la culture digitale. Dans les paragraphes qui suivent vont être abordés les thématiques de la couverture et de son dispositif, de l'index, de la note de bas de page et de la référentialité, puis finalement de la mutation de l'écriture via la multimodalité et le code informatique. Ces divers points déclineront et illustreront ce que l'on quitte, ce que l'on garde et qui mute, et ce que l'on acquiert, dans le séisme en cours des expérimentations de l'écriture digitale.

\footnotetext{
144 En paraphrasant le titre de l'article de Rouvroy, « La vie n'est pas donnée ».

145 L'impact du design sur l'écriture est aussi un point très important. Voir par exemple R. Badouard et J. Longhi, « Débat public et écritures numériques. Design, interfaces et créativité », Les Cahiers d'Agora : revue en humanités 1 (2018), <https://www.u-cergy.fr/fr/ laboratoires/agora/cahiers-d-agora/numero-1/debat-public-et-ecritures-numeriques-de sign-interfaces-et-creativite.html>.

146 Voir chapitre 4, point 2.
} 


\subsection{Ce que l'on quitte : la couverture et son dispositif}

La couverture est en général notre premier contact physique avec un livre, qu'on le saisisse par sa reliure sur une étagère, ou à pleines mains par sa couverture de face. L'image, le titre, la matière de la couverture guide nos premiers contacts avec l'objet livre. De manière évidente, renoncer à tenir une couverture dans ses mains est le premier choc de la perte tactile de l'objet livre. Ce choc est si dantesque qu'il justifie à lui seul le fait très probable que l'objet livre perdurera, sous quels usages et modalités, nous le verrons bien, mais fort en tout cas de son statut d'objet non connecté, petite victoire sur les liens de la « toile d'araignée ».

En même temps, des signaux non anodins nous parviennent d'une prise de congé partielle de l'objet livre dans son rôle dominant et usuel. Ces signaux sont parfois surprenant : les bouquinistes des quais parisiens, institutions du livre s'il en est, ne vendent plus ce qu'il faudrait pour assurer leur pérennité147, et voici que Paris a entamé la longue démarche pour les voir inscrits au « patrimoine immatériel de l'humanité » par l'Unesco ${ }^{148}$. Qu'on arrive à proclamer des livres et leurs vendeurs patrimoines immatériels de l'humanité nous conduit à une nouvelle illustration de l'oxymore d'Olender, les « documents matériels immatériels ${ }^{149}$. Alors que nous découvrons au fur et à mesure les évolutions du devenir du livre, et sans aucunement penser qu'il disparaîtra, il est toutefois réaliste de considérer comme un choc sensoriel le fait que nous sommes de moins en moins appelés à tenir dans nos mains une couverture de livre, un choc que j'ai étudié dans un article précédent ${ }^{150}$.

En résumé, les sentiments suscités par la perte de la couverture se disent comme un séisme et une angoisse, des sentiments soulignés par Jacques Derrida pour exprimer ce que nous fait la sortie du papier ${ }^{151}$; cette sortie atteint la mémoire culturelle occidentale dans la solidarité forte qu'elle décline entre le livre et le corps ${ }^{152}$. Mais sortir du papier est aussi formulé comme un rêve par Derrida à la fin de son texte : « Je rêve donc aussi de vivre sans papier - et cela

147 A. Cargoet, «A la rencontre des bouquinistes des quais de Seine, un métier en danger », Les Inrockuptibles, 13 août 2017, <https://www.lesinrocks.com/2017/08/13/actualite/re portage-chez-les-bouquinistes-des-quais-de-seine-un-metier-en-danger-11973785/> .

148 O. Boittet, «Bientôt une inscription des bouquinistes de Paris au patrimoine de l'Humanité ? », Le Parisien, 2 mai 2018, <http://www.leparisien.fr/paris-75/bientot-une-inscription-des-bouquinistes-de-paris-au-patrimoine-de-l-humanite-02-05-2018-7694751. php>.

149 Olender, Un fantôme, p. 28 ; cité au chapitre 1, p. 27 et au chapitre 2, p. 57 et 60.

150 Clivaz, « En quête des couvertures et corpus », 2015 ; traduction anglaise : Clivaz, « Covers and Corpus wanted », 2016.

151 Voir l'Introduction, p. 4.

152 Clivaz, «En quête des couvertures et corpus », p. 104. 
sonne parfois à mes oreilles comme une définition de la 'vraie vie', du vivant de la vie $»^{153}$.

A se dégager de la couverture, on rencontre une certaine force d'utopie qui, premièrement, nous remet en mémoire les liens millénaires du texte à l'oralité, comme je l'ai souligné avec plusieurs exemples, notamment l'impact de la performance orale sur les manuscrits mêmes d'Hamlet de Shakespeare ${ }^{154}$. Deuxièmement, ce dégagement de la couverture réinscrit le texte dans le réseau de commentaires qui l'entourent, dans une architextualité, pour reprendre la terminologie de Genette ${ }^{155}$, qui aura été usuelle avant que la culture imprimée n'atteigne le sommet de son règne : cette architextualité dominante en Occident se repère dans des objets tels que le Codex Zacynthius (6e siècle de notre ère, palimpseste $)^{156}$, où le texte de l'Evangile selon Luc apparaît au centre de pages dont les bords sont faits de commentaires patristiques, ou dans l'importance accordée aux commentaires ou annotationes, par exemple chez Erasme $^{157}$.

Une fois émancipé de la clôture de la couverture, le texte ne se retrouve donc pas libre de tout lien, bien au contraire. De nouvelles alliances et de nouveaux liens se refont très vite sur la toile : en 2009, le théologien protestant Olivier Abel avait dressé de manière convaincante le portrait des pirates surfeurs sur le net dans les habits des flibustiers du 17e siècle. Les conditions territoriales - physiques et numériques, océans d'eau et de pixels - se ressemblent en effet :

Sur l'océan il n'y a plus ni roi ni pape, on est seul avec Dieu, on a tout quitté. Obligés de vivre chaque jour sans être trop assurés du lendemain, on sait vite qu'il est impossible de s'approprier la mer, de la retenir entre ses doigts. Les individus cependant sont ainsi déliés pour contracter des

153 Derrida, « Le papier ou moi », p. 57.

154 Clivaz, « En quête des couvertures et corpus », p. 102 : « Paul Eggert a récemment présenté une synthèse de la situation des trois premières éditions imprimées de la pièce [de Hamlet de] 1603, 1604-05, and 1623. La première représente sans doute l'adaptation d'une pièce jouée le 26 juillet 1602 , probablement reconstruite de mémoire par les acteurs de la pièce et préparée pour être vendue à un éditeur, Nicholas Ling. Par contre, les versions plus longues et notamment la seconde édition, pourraient être des versions littéraires conçues consciemment pour la lecture, plutôt que pour la scène ».

155 G. Genette, Introduction à l'architexte, Seuil, 1979.

156 Voir pour une description de ce manuscrit D. C. Parker, « The Date of Codex Zacynthius $(\Xi)$ : A New Proposal », dans Manuscripts, Texts, Theology. Collected Papers 1977-2007 (ANTT 40). D. C. Parker (éd.), de Gruyter, 2009, p. 113-119. Pour son édition : S. P. Tregelles, Codex Zacynthius. Greek Palimpsest Fragments of the Gospel of Saint Luke, London : Samuel Bagster \& Sons, 1861.

157 Clivaz, « En quête des couvertures et corpus », p. 103. 
alliances nouvelles, des libres alliances : le droit de partir est la condition du pouvoir de se lier. Et la grande question politique deviendra alors peu à peu « comment rester ensemble » alors qu'on peut toujours partir, se délier ${ }^{158}$.

Au 17e siècle, précise-t-il, « parce que sur l'océan tout se délie, que tout est sans cesse délié, il faut repenser les amarres, les attaches, les cordes, les nœuds, et les pactes ${ }^{159}$. Sur l'océan d'internet, les vagues de la culture digitale conduisent à repenser sans cesse les liens, amarres et attaches, en particulier entre le corps et le support digital, le corps devenant le lieu même qui « résiste, encore et toujours, et dit sa présence en hybridité à la machine ; alors le geste de la clôture, de la délimitation - si fondamental pour éviter la folie de la dispersion - doit être toujours possible ${ }^{160}$. La disruption soulignée par Stiegler pourrait notamment se jouer dans un retrait brutal de la couverture, nous poussant à la quête effrénée de nouvelles délimitations au discours, oral, imagé ou écrit. Les personnages du roman de science-fiction Fahrenheit 451 offrent une parabole illustrant la possibilité du corps-couverture, du corps-clôture : ils deviennent les chapitres de livres qu'ils ont appris par cœur, dans un univers mortifère où les livres sont pourchassés pour être brûlés ${ }^{161}$.

Dans ce roman précurseur, voici les textes ramenés aux personnes ellesmêmes, sur fond d'incendie dramatique du savoir livresque. La sortie du papier et la migration de l'archivage des textes vers les êtres humains peuvent toutefois être décrites aussi comme des utopies positives, via les mots de Derrida qui rêve de « vivre sans papier », « la 'vraie vie', [le] vivant de la vie ». Cet archivage humain, encore mémoriel et figuré chez Bradbury, prend un tournant tout incarné depuis 2012 où on a vu apparaître les premiers stockages de données dans de l'ADN ${ }^{162}$. Nous aurons encore besoin d'années ou décennies pour vérifier, individuellement et collectivement, si vivre sans papier est un rêve ou un incendie magistral, ne serait-ce qu'en pensant aux conséquences écologiques de l'empreinte énergétique des objets digitaux, un thème qui ne peut qu'être pris de plus en plus en compte ${ }^{163}$.

Mais une tension grandissante par rapport à l'objet-couverture que l'on quitte se laisse percevoir chaque jour davantage, notamment à travers

\footnotetext{
158 Abel, « Essai sur la prise », p. 114-115.

159 O. Abel, « L'océan, le puritain, le pirate », Esprit 356 (2009), p. 104-110.

160 Clivaz, « En quête des couvertures et corpus », p. 106.

161 Bradbury, Fahrenheit 451, 1953. Voir le chapitre 1, p. 19.

162 Voir N. Goldman et al., « Towards practical, high-capacity, low-maintenance information storage in synthesized DNA », Nature 494 (2013), p. 77-80, <https://www.nature.com/arti cles/nature11875>.

163 Le $W_{3} C$ Community Group essaie par exemple de stimuler la réflexion sur ce thème parmi les acteurs du World Wide Web 3.o, <https://www.w3.org/community/wwca/>.
} 
l'initiative «Living Library», annoncée au festival littéraire de Soleure 2018 avec le slogan «never juge a book by its cover » 164 ! Le projet « Living Library » a démarré dans les années 2000, au moment où des activistes danois ont lancé la «Human Library », pour tenter de briser les présupposés et stéréotypes engendrés par le racisme et le sexisme ${ }^{165}$. Des animateurs se présentent autour d'une table de café, tels des « livres vivants », d'âges, de milieux sociaux et culturels différents et présentent un livre, qui peut ensuite être emprunté, un processus décrit dans une vidéo d'amorce sur YouTube ${ }^{166}$. On est ici très proche des «humains livres » ou «livres humains » de Fahrenheit 451, à ceci près que le héros, le pompier Montag, se rappelle de quelques passages de la Bible, provenant de l'Apocalypse et de l'Ecclésiaste ${ }^{167}$. Entre les souvenirs de Montag et l'entreprise de la « Living Library » se tient un tournant culturel, où la référence aux Ecritures bibliques se modifie en profondeur, sans qu'il ne soit aisé d'en prédire le devenir exact ${ }^{168}$.

L'heure est à la superposition de l'humain et de la littérature, que cela soit via la porosité du « je » d'auteur pris dans la tourmente des performances de tous ordres ${ }^{169}$, ou via des initiatives comme celles-ci. Face à ces évolutions rapides, force est de constater que sortir de la couverture et de tout le dispositif qui l'accompagne, c'est sortir d'un système de surveillance patenté. Composé de la couverture, la page de garde (ou première et dernière de garde), la page de faux titre, la page de titre, l'achevé d'imprimer, la quatrième de couverture, ce dispositif a pu servir aussi à souligner la richesse d'un volume, la page de faux titre pouvant servir, selon Madeleine Sauvé, de « frontispice du pauvre », alors que la page de titre frontispice, « introduite au 17e siècle», pouvait être « entièrement gravée, portant décoration et écriture ${ }^{170}$. C'est donc tout un monde qui se joue et s'est joué dans ce dispositif bien « gardé », dans un geste fait à la fois de surveillance et de protection, car la couverture dit aussi la collection et l'éditeur, si importants à la reconnaissance académique ou littéraire.

164 Voir Living Library, <https://www.livinglibrary-so.ch/>.

165 Ces informations se trouvent réparties sur ces différents sites : $<$ http://www.scich.org/de/ einsatz-schweiz/freiwilliges-engagement/Projektgruppe-living-library/>; <https:/www. livinglibrary-so.ch/\%C3\%BCber-uns/>; <https://www.facebook.com/events/1914065902 $239698 />$.

166 Voir <https://www.youtube.com/watch?v=xtNT--lp_cs >.

167 Bradbury, Fahrenheit 451, p. 143: «'You want to join us, Montag ? 'Yes'. 'What have you to offer?' 'Nothing. I thought I had part of the Book of Ecclesiastes and maybe a little of Revelation, but I haven't even that now' ‘The Book of Ecclesiastes would be fine. Where was it? ' 'Here'. Montag touched his head ».

168 Voir chapitre 4, point 2.3.2.

169 Voir la p. 118 ci-dessus.

170 M. Sauvé, Qu'est-ce qu'un livre?, Fides, 2006, p. 107. 
On voit ici très clairement ce que l'on quitte avec le retrait de la couverture, de l'aspect sensoriel à la dimension de protection de ce lieu d'entrée dans le livre. On verra ce qui, au juste, remplacera ce dispositif de clôture, de surveillance et de protection du texte. Gageons en tous cas que ces besoins fondamentaux dans notre usage des textes ne disparaîtront pas, mais qu'ils sont d'ores et déjà recyclés, métamorphosés.

\subsection{Ce qui traverse les mutations des supports d'écriture et s'adapte: l'index, la référentialité}

La liste des traits du livre traversant les modifications du support d'écriture et de publication est longue, et charrie avec elle des traits précédents le livre et lui survivant, comme l'index. On a vu au point 4.1 que même en ce qui concerne la couverture et son dispositif, dissous en tant que tels dans le monde numérique, il faut compter sur la pérennité des besoins auxquels ils répondaient - clôture, surveillance, protection -, sans qu'il ne soit encore possible de cartographier la métamorphose numérique de ces besoins. Au chapitre 4, nous verrons que la notion de corpus est également l'objet d'un départ, d'un adieu, mais doit et va se recomposer dans une variété de collections digitales.

D'autres notions ont un usage plus évident, traversant les siècles et les supports d'écriture, et sans qu'on n'ait le sentiment de les quitter, au contraire. C'est le cas de l'index, le point qu'Olivier Le Deuff utilise pour « faire débuter » les humanités digitales, comme nous l'avons vu au chapitre $2^{171}$. Avec ce choix, il annonce d'emblée vouloir dépasser la référentialité à l'informatique et adopter un point de vue historique transversal :

La question des humanités digitales dépasse la seule vision informatique adossée aux sciences humaines et sociales. Réduire cette histoire à l'apparition des outils informatiques et à leur utilisation par les chercheurs en sciences humaines et sociales ne permet pas de comprendre les filiations ainsi que les nombreuses tentatives interdisciplinaires et transdisciplinaires qui ont permis d'introduire des méthodes de compréhension et d'analyse nouvelles ${ }^{172}$.

De fait, c'est tout l'appareillage du livre qu'il reconsidère au travers de l'index, soulignant les liens de ce dernier au visuel et au design ${ }^{173}$. Comme Anthony Masure l'a récemment souligné,

171 Le Deuff, Les humanités digitales, p. 35 ; cité au chapitre 2, p. 53.

172 Le Deuff, Les humanités digitales, p. 10.

173 Le Deuff, Les humanités digitales, p. 46. 
A la croisée de l'informatique et des sciences humaines et sociales, les humanités numériques ne se sont que trop peu préoccupées de questions propres au design. Au-delà d'une approche utilitaire, la constitution d'archives et de corpus de connaissances en ligne est pourtant l'occasion de s'interroger sur les rôles que peuvent jouer les designers au sein de ces projets. A l'heure d'une numérisation du monde marquée par une oligarchie des plateformes, les humanités numériques et le design devraient ainsi œuvrer à dérouter la captation des connaissances et les déterminismes technologiques ${ }^{174}$.

Par ailleurs, la fonction de recherche de l'index le relie de manière privilégiée aux humanités digitales : «Les humanités digitales s'inscrivent donc dans le mouvement qui fait que si nous ne pouvons pas tout lire exhaustivement, nous pouvons sans cesse chercher et rechercher ${ }^{175}$. L'exploitation de la notion d'index par Le Deuff met donc en scène et explicite une notion importante, qui traverse les mutations du support d'écriture. D'autre part, son analyse culmine de manière judicieuse dans ce que nous sommes de plus en plus nombreux à souligner, soit l'architextualité de l'hypertextualité :

L'hypertexte est en fait un puissant architexte, c'est-à-dire une forme ou un dispositif conçu par d'autres, il y a parfois longtemps, mais que nous continuons d'utiliser sous des aspects qui ont évolué au fil du temps. Il a poursuivi sa mutation au sein de différents environnements. Il incite au parcours et à des lectures non linéaires, ce qui le relie à l'index ${ }^{176}$.

Les étonnantes petites manicules des manuscrits antiques et médiévaux ${ }^{177}$ signalent bien l'envie d'avoir plusieurs niveaux dans le texte, de laisser émerger «par-dessus » le reste des phrases certaines informations. En ce sens, l'hypertexte électronique accomplit matériellement le désir et les fonctions d'architextualité repérables au long des siècles, notamment via l'usage de l'index, apparu avec le codex, et des manicules.

La situation est un peu différente en ce qui concerne la référentialité, qui est, elle aussi, une aspiration traversant siècles et mutations des supports d'écriture, mais qui s'exprime bien différemment, ou en tout cas avec une précision bien variable, en fonction des possibles de chaque support d'écriture et

174 A. Masure, «Vers des humanités numériques 'critiques' », AOC 5 juillet 2018, <https://aoc. media/analyse/2018/07/05/vers-humanites-numeriques-critiques/>.

175 Le Deuff, Les humanités digitales, p. 45.

176 Le Deuff, Les humanités digitales, p. 40.

177 Pour une illustration de manicule, voir Le Deuff, Les humanités digitales, p. 40. 
de publication. En préambule, il faut souligner que la référentialité a toujours été une préoccupation: Paul Veyne a, en son temps, proposé une magistrale relecture de l'appréhension du réel dans la culture antique, dans Les Grecs ontils cru en leurs mythes ?178 Il y soulignait notamment que ni Aristote, ni Pausanias, cinq siècles plus tard, n'avaient douté de l'existence de Thésée, pas plus que Thucydide ${ }^{179}$. Quant à Tite-Live ou Denys d'Halicarnasse, ils présumaient que leurs prédécesseurs disaient vrai, en corrigeant ce qu'il fallait dans leurs propos $^{180}$.

A ces exemples, on peut ajouter encore celui du médecin du 2e siècle de notre ère, Galien, qui illustre parfaitement la manière dont un auteur antique est attaché à la propriété de ses idées - comme tout auteur à travers les siècles - mais n'a juste aucun moyen concret de pouvoir en garantir la propriété181. Il se montre par ailleurs attaché à la scientificité, discutant longuement de l'existence des Centaures reconnus par certains, ou s'insurgeant contre l'usage de la poésie pour tenir un discours de la preuve ${ }^{182}$.

Mais force est de constater que l'aspiration à la référentialité va connaître un virage décisif à l'orée de la modernité, une fois l'imprimerie inventée : vers 1560, Etienne Pasquier inaugure la référentialité méthodique aux sources précédentes, au grand dam de ses amis ${ }^{183}$. Comme le souligne Anthony Grafton, Pasquier, dans son édition révisée de ses Recherches de la France (1596), doit justifier pourquoi il se réfère tout le temps à quelque auteur ancien pour justifier ses dires ${ }^{184}$. Qu'il ait dû batailler comme il le dit ou dans une moindre mesure, qu'importe : la culture de la référentialité systématique était lancée, qu'on se pique de faire de l'histoire comme Pasquier, ou une pièce de théâtre historique comme Ben Johnson (1605) ${ }^{185}$. Par l'étendue des textes mis en circulation, la culture imprimée imposera petit à petit la référence systématique. A travers les siècles et les supports d'écriture, que la référentialité soit ponctuelle ou systématique, qu'elle se dise à travers des notes de bas de page ou de simples annotations, elle repose toujours sur des conventions ancrées dans une cer-

178 P. Veyne, Les Grecs ont-ils cru à leurs mythes? Essai sur l'imagination constituante, Seuil, 1983.

179 Veyne, Les Grecs ont-ils cru, p. 26 et p. 143.

180 Veyne, Les Grecs ont-ils cru, p. 19.

181 C. Clivaz, «Peut-on parler de posture littéraire pour un auteur antique ? Les exemples de Paul de Tarse, de Galien et un auteur anonyme », Contextes 8 (2011), <http://contextes.re vues.org/index4722.html>.

182 Veyne, Les Grecs ont-ils cru, p. 72-73.

183 Veyne, Les Grecs ont-ils cru, p. 18.

184 A. Grafton, The Footnote. A Curious History, Harvard University Press, 1997, p. 142.

185 Grafton, The Footnote, p. 142-144. 
taine culture, comme l'a rappelé Jacques Derrida dans une conférence américaine en 1988:

Le concept d'annotation stricto sensu (si une telle signification existe) a des limites imposées par certaines lois, institutions et conventions sociales qui ont leur propre histoire et leurs propres limites culturelles bien déterminées. [...] D’autres cultures - même par exemple les cultures juive et arabe, peu éloignées de la nôtre - se servent d'une organisation intertextuelle de la page en élaborant une mise en page topographique suivant des règles et des évaluations d'ordre hiérarchique qui sont très loin de correspondre à ce que nous appelons annotation ${ }^{186}$.

Poser une hiérarchie et une relation d'autorité dans le texte tient, pour Derrida, d'un modèle «théologico-politique »: « La loi qui gouverne cette hiérarchie et qui implique la spatialisation en général, même dans les actes de parole, même dans des affirmations purement orales - lie l'auteur du texte principal, le Dieu du texte annoté, aux subordonnés, aux esclaves, aux annotateurs étrangers $»^{187}$. En plus de cette hiérarchie, quasi sacralisée ici, force est de constater que la note de bas de page de la modernité aura fait de nous des « croyants », voir des « crédules ». C'est dans une minorité des cas que nous aurons vérifié si le contenu proposé par la note était bel et bien en concordance avec la source. Léducation à la culture imprimée nous a en effet inculqué l'habitude de faire confiance à la note de bas de page.

Quand malgré tout nous allons vérifier la source, des surprises peuvent être au rendez-vous : en 2010, j'avais enquêté à propos d'une améthyste antique portant une image du Christ, incluse dans une liste d'archanges. Répertoriée depuis plus d'un siècle dans des encyclopédies cotées et les monographies contemporaines, la pierre est à chaque fois bien décrite, couleur incluse ${ }^{188}$. Or la dernière fois que quelqu'un l'a vue, c'est Julien Durand à l'Exposition Universelle de $1878^{189}$ ! Depuis, toutes les sources se sont contentées de répéter la description de Durand, l'objet ayant, jusqu'à plus ample informé, disparu de la circulation ${ }^{190}$. Difficile de dire si cet exemple radical se répète : c'est tout à fait par hasard que j'avais vérifié cette référence, curieuse de voir l'objet.

186 J. Derrida, «Ceci n'est pas une note infrapaginale orale», dans L'Espace de la note (La Licorne 67), J. Dürrenmatt - A. Pfersmann (dir.), S. Pickford (trad.), 2004, p. 7-20; ici p.11-12. Derrida, « Ceci n'est pas », p. 9.

188 Voir par exemple D. D. Hannah, Michael and Christ: Michael Traditions and Angel Christology in Early Christianity (WUNT II 109), Mohr Siebeck, 1999, p. 172-173.

189 J. Durand, «Les sept anges », Bulletin Monumental 50 (1884), p. 767-772 ; ici p. 770.

190 Clivaz, L'ange et la sueur de sang, p. 161-162. 
En tous les cas, un exemple de ce type devrait nous rendre prudents devant l'énergique «coup de gueule» d'Eco face au World Wide Web qui ne permettrait plus « aucune distinction désormais entre vérité et erreur »191, ou lorsque le philosophe suisse Jean Romain considère que le virtuel souhaite remplacer la réalité ${ }^{192}$. La couverture du livre, certifiée par une collection reconnue, et ses soldats en ordre de marche, les notes de bas de page, semblaient garantir le réel ; or le virtuel, précisément parce qu'il floute la frontière entre réel et fiction, nous invite à un perpétuel mouvement de vérification. Il nous faut sans cesse confronter les informations en ligne avec d'autres sources, un geste dont la note de bas de page nous avait trop souvent dispensés. Pourtant ce patient travail de vérification et de confrontation n'est rien d'autre que la mise en œuvre du jugement de la communauté qui assure les frontières du réel, communauté décrite en son temps par le philosophe Charles S. Peirce comme « sans limite et capable d'augmenter indéfiniment la connaissance ${ }^{193}$.

L'effacement et la mutation de la note de bas de page nous rendent à cette tâche. Toutefois, il faut bien reconnaitre que la référentialité est, dans ces années de transition vers l'écriture digitale, bien malmenée et peu encore outillée et honorée comme elle le mériterait. Cette phase hésitante est due à deux facteurs principaux. Premièrement, l'ordinateur tend à rendre l'annotation et la référence à l'oralité, un point que Derrida souligne en précurseur. Reconnaissant les liens de l'annotation et de la note de bas de page à « l'économie et à la technologie de l'imprimerie », il note que « l'ordinateur rend possible l'intégration fluide de la digression ou du rajout dans l'écriture linéaire $»^{194}$. Derrida met de plus en avant l'idée perspicace que l'ordinateur, dans cette évolution, rapproche de l'oralité : « [l'ordinateur] protège et même prolonge l'autorité de l'écriture phonétique linéaire en lui conférant une capacité accrue d'intégration, et en fin de compte plus de proximité à la voix ou à l'acte de parole stricto sensu $» .195$

Faire en 1988 une telle observation tenait du regard précurseur : on accumule aujourd'hui les preuves de la proximité, la porosité, la mixité de l'écriture digitale par rapport à l'oralité, d'où une certaine approximation, voire des omissions parfois, dans la manière de référencer le savoir. On en prendra pour

191 Eco, Vertige de la Liste, p. 360; cité au chapitre 1, p. 25.

192 J. Romain, «La priorité pour l'école n'est pas d'enseigner le numérique », Le Temps, 28 octobre 2016, <https://www.letemps.ch/opinions/jean-romain-priorite-lecole-nest-den seigner-numerique $>$.

193 N. Houser et alii (éd.), The Essential Peirce. Selected Philosophical Writings, vol. 1, Indiana University Press, 1992, p. 52.

194 Derrida, « Ceci n'est pas », p. 13.

195 Derrida, « Ceci n'est pas », p. 14. 
exemple l'article de Bertina et Bon publié dans Les Cahiers d'Agora : il est composé d'une vidéo à l'état brut, d'une durée d'une heure, sept minutes et vingthuit secondes. Le contenu est passionnant, mais il n'y a aucun moyen de citer par référence électronique un passage précis de la vidéo, ni d'avoir accès au texte de la vidéo pour chercher dans le propos des conférenciers ; ce texte aurait au moins pu être retranscrit via des moyens semi-automatiques ${ }^{196}$. Alors que l'écriture académique a tant soigné et tant développé l'art de la note de bas de page, c'est comme si elle était démunie devant la production orale, de laquelle l'écriture computationnelle nous rapproche, comme l'annonçait Derrida en 1988. On ne compte plus la masse de matériel académique passionnant accessible en vidéos, mais non cherchable et non citable en détail.

C'est devant cet état de fait que j'ai pu développer tout d'abord en collaboration avec Frédéric Kaplan et Cyril Bornet (EPFL), puis avec Martial Sankar, Marion Rivoal et Cécile Pache (sıB) les " eTalks », un outil de publication multimédia entièrement citable en détails ${ }^{197}$. A l'aide du logiciel Audacity, le discours oral d'un/e chercheur/se est découpé automatiquement en morceaux d'une, deux ou trois phrases, en suivant le rythme du souffle de l'orateur/rice. Les phrases sont ainsi regroupées en "phrasés », selon le terme utilisé en musique. Le discours oral incarné, au rythme du souffle, dicte ici la rédaction du texte, également édité dans l'eTalk, et chaque phrasé se retrouve également associé à un slide, avec des hyperliens. Autrement dit, l'objet inaugure la référence multimodale, cette notion nouvelle que peut véhiculer l'écriture digitale et qui est abordée au point suivant.

Le deuxième facteur qui rend hésitante la mutation de la note de bas de page et de nos moyens de référencer est l'expérience complexe de l'hyperlien. L'hyperlien défait l'organisation hiérarchique de la page. Il ajoute de l'information à tout moment, et celle-ci passe ainsi du statut de supplément ou d'ajout, depuis son lieu préservé du hors-texte, à celui de «texte en plus», de texte ailleurs, d'intertexte. Et ce naturellement, quand il fonctionne. Cette intertextualité - au sens littéral du terme - permise par l'hyperlien est une gageure pour l'auteur et pour le lecteur. Lauteur doit céder de sa superbe et de son

196 Bertina - Bon, « Mais comment diable», <https://www.u-cergy.fr/fr/laboratoires/agora/ cahiers-d-agora/numero-1/mais-comment-diable-s-y-prennent-ils-face-a-face-entre-lesdeux-ecrivains.html>.

197 Voir C. Clivaz - M. Rivoal - M. Sankar, « A New Platform for Editing Digital Multimedia: The eTalks », dans New Avenues for Electronic Publishing in the Age of Infinite Collections and Citizen Science, B. Schmidt - M. Dobreva (éd.), Ios Press, 2015, p. 156-159; <http:// www.ebooks.iospress.com/publication/40894>; Clivaz et al., «Multimodal literacies and academic publishing », <http://content.iospress.com/articles/information-servicesand-use/isu $781>$. 
pouvoir au lecteur, qui d'un clic peut se retrouver lui aussi face à la source, face à l'autre texte, le lire, l'interpréter et en rendre compte. Aussi le lecteur ne peut plus se permettre de se reposer paresseusement sur la note de bas de page et son contenu : s'il peut vérifier, il doit désormais vérifier. Comme je l'exprimais dans un billet de blog, « la note de bas de page était le filet tendu au milieu du court dans la partie entre l'auteur et le lecteur. L'hyperlien les aligne l'un sur l'autre comme scribe en action et scribe à venir ${ }^{198}$. Sauf à renoncer à jouer notre rôle dans la communauté Piercéenne qui délimite les frontières du réel, nous ne pouvons pas nous dédouaner de la quête de la référence et de sa vérification: ce besoin millénaire traverse les soubresauts les plus rudes de ses nouvelles formes d'expression numérique.

\subsection{Ce qu'on acquiert: la multimodalité et le code}

Observer toutes les nouveautés et potentialités de l'écriture digitale engendre une fascination qui occupera encore longtemps notre génération. Je choisis d'aborder ici les deux points qui, au cours de ces dernières années, m’ont paru les plus marquants en termes de modification, un mot qu'on peut entendre ici en écho au récit de Michel Butor ${ }^{199}$. Il s'agit d'une part de la multimodalité, que permet et provoque l'écriture digitale qui devient ainsi un processus global qui sort d'une définition liée au texte à proprement parler. D’autre part, nous aborderons la notion de code informatique et d'écriture digitale encodée, la grande mutation en cours de l'écriture sur support numérique.

L'arrivée d'une manière d'écrire capable de mêler texte, image et son est une révolution, et qui n'est que depuis peu de temps, finalement, au cœur des projets et préoccupations des Digital Humanities. Pendant deux générations, celles où l'on parlait de Humanities Computing (1945-2000), les tâches récurrentes des DH ont été centrées sur les textes et la textualité, qu'il fallait encoder, indexer, mettre en liste, classer. En 2004, dans la première édition du Compagnion to Digital Humanities, Roberto Busa désigne la textualité comme la tâche centrale des Humanities Computing, qui « sont précisément l'automatisation de toute analyse possible de l'expression humaine - c'est pourquoi il s'agit d'une activité 'humaniste' par excellence - dans le sens le plus large du terme, de la musique au théâtre, du design à la peinture et à la phonétique, mais dont le noyau demeure le discours des textes écrits ${ }^{200}$.

198 C. Clivaz, «Au-delà de la note de bas de page », Le Temps 23 novembre 2017, <https:// blogs.letemps.ch/claire-clivaz/2017/11/23/la-perte-de-la-note-de-bas-de-page/>.

199 M. Butor, La modification, Editions de Minuit, 1957.

200 Busa, « Foreword», <http://www.digitalhumanities.org/companion/>. 
Il ne fait nul doute que cette description est toujours valable en ce moment, mais 2004 a aussi été l'année de l'émergence dans les publications de l'expression digital humanities, et d'autres chercheurs ont commencé à percevoir le tsunami multimodal de l'écriture digitale s'annoncer à l'horizon, telle Kathleen Fitzpatrick en 2009 :

Si nous avions la capacité de pouvoir répondre à une vidéo par une vidéo, si nous pouvions passer sans heurt de fichiers audio à des images et à un texte comme moyens de représenter de la musique, cela pourrait nous permettre de penser de la manière exacte dont nous produisons lorsque nous écrivons: faire advenir ces différents modes de communication dans des formes documentaires communes complexes ${ }^{201}$.

Un tel point de vue semble a posteriori prophétique, alors qu'on nous annonce que, dès 2020, plus des trois quarts des données circulant sur internet seront du matériel audio-visuel ${ }^{202}$. Pressentant le tsunami multimodal, de plus en plus de chercheurs cherchent à l'exprimer, par exemple Kenneth Goldsmith :

Ce que nous prenons pour des images, des sons ou des déplacements dans le monde des écrans n'est qu'une peau très fine sous laquelle s'empilent des kilomètres et des kilomètres de langage. [...] Ce que nous expérimentons pour la première fois, c'est la capacité du langage à déformer tout autre média, qu'il soit image, vidéo, musique ou texte, quelque chose qui représente une rupture avec la tradition et ouvre la voie à de nouveaux modes d'emploi du langage. Les mots sont actifs et affectifs de façon concrète. Vous pouvez prétendre que ce n'est pas de l'écriture au sens traditionnel, vous aurez raison. Mais c'est en cela que les choses deviennent intéressantes. Nous ne sommes pas en train de divaguer sur des machines à dactylographier; bien plutôt, accaparés des journées entières sur des machines puissantes, aux possibilités infinies, reliées à des réseaux au nombre également infini de possibles : voici pour l'écrivain de nouveaux défis, significativement accrus et réactualisés ${ }^{203}$.

201 Fitzpatrick, Planned Obsolescence, p. 27 : « if we have the ability to respond to video with video, if we can move seamlessly from audio files to images to text as means of representing music, it may behoove us to think about exactly what it is we're producing when we write, how it is that these different modes of communication come together in complex document forms ».

202 IBM Market Insights 2013, <https://avindhsig.wordpress.com/background/>.

203 Goldsmith, L'écriture sans écriture, p. 25 et 32. 
Pour répondre à ces nouveaux défis d'écriture en contexte académique, on assiste au développement d'éditeurs multimodaux, tels les eTalks, présentés en 4.2, ou Scalar ${ }^{204}$. La révolution d'une connaissance multimodale est en marche, mais va prendre certainement encore du temps en milieu académique, tant l'opération est complexe du point de vue épistémologique. Du point de vue culturel, les objets multimodaux commencent à être de plus en plus nombreux, complexes et passionnants, comme les productions du Lab du journal suisse Le Temps. L'excellent reportage multimédia sur l'Erythrée, dans une formule « Lab», permet par exemple à l'utilisateur de décider à quel rythme il/ elle le visite, rythme des images, du texte et du son n'étant pas liés de bout en bout, mais regroupés par étapes ; par ailleurs, la voix de la journaliste se fait plus poétique et émotionnelle, alors que l'information écrite, rédigée par une autre journaliste, est plus factuelle et descriptive : là aussi, à l'utilisateur de déterminer le point de vue auquel il/elle adhérera le plus au bout du compte ${ }^{205}$.

Du côté artistique, on ne compte plus les explorations de nouvelles formes de création multimodales, notamment les productions de l'écrivain François Bon, en particulier « Où le monde double s'effondre », une vidéo d'un peu plus de cinq minutes où se croisent des peintures de Pierre Ardouvin, la musique de Chopin, un texte de Marcel Proust lu par Bon, et finalement un quatrième niveau d'information composé par des phrases rédigées par l'auteur et qui traversent l'écran de temps à autre ${ }^{206}$. La voix auctoriale a clairement gardé sa place ici, même si elle croise et se mêle à d'autres instances de production, dans une claire répartition de l'espace visuel et auditif.

Autant le dire d'emblée, un tel objet est d'une complexité de lecture à laquelle nous ne sommes pas encore habitués, du moins couramment, car la culture et musique rap, par exemple, en produit depuis un certain temps déjà. Il faut écouter/regarder plus d'une fois « Où le monde double s'effondre » pour en saisir toutes les nuances et intrications de sens. Afin d'habituer les étudiants et chercheurs à interpréter des objets multimodaux, j'ai bâti avec Martial Sankar un module d'enseignement sur ce thème, qui a pris place dans une plateforme web, \#dariahTeach, développée dans le cadre d'un Erasmus+. Ce cours permet aussi d'apprendre à produire et éditer des objets culturels multimodaux via les etalks ${ }^{207}$.

\footnotetext{
204 Voir Scalar, <http://scalar.usc.edu/>.

205 S. Buret - V. de Graffenried - V. Botteron - J. Abbiateci, « Voyage en Erythrée. Un reportage photo de Stéphanie Buret », Le Temps interactif (2016), <https://labs.letemps.ch/interac tive/2016/erythree/>.

206 F. Bon, « Où le monde double s'effondre», YouTube 23 janvier 2016, <https://www.you tube.com/watch?v=7-IydGzDhbw>.

207 C. Clivaz - M. Sankar, «Multimodal Literacies. Course », \#dariahTeach, 27 mars 2017, $<$ https://teach.dariah.eu/course/view.php?id=24>.
} 
Si ces objets nous apparaissent complexes, c'est parce que les sciences humaines étudient déjà avec intensité ce qu'il advient entre écriture et image, un sujet complexe en tant que tel, ou via l'utilisation des sources sonores, ou de l'oralité, fortement présente dans ce chapitre. Nous avons premièrement vu avec Derrida que « dès que je parle, je trahis [...et] c'est à cette condition que [la trace] devient littérature », parole et écriture étant ici perçues dans un continuum $^{208}$, l'ordinateur rapprochant même la référentialité de l'oralité, selon Derrida ${ }^{209}$. Nous avons ensuite constaté avec Meschonnic combien l'oralité déterminait l'écrit, notamment dans le texte de la Bible hébraïque, nous rappelant sans cesse le rythme de nos productions. Puisque le retour de la perception de l'oralité dans la communication écrite contribuait à rendre le «je » auctorial de plus en plus poreux dans la culture digitale, où les discours s'enchaînent tels un flux. C'est ce flux numérique que met en scène l'essai novateur de Marina Skalova, Exploration du flux $x^{210}$, où le graphisme du texte imprimé tente de rendre le rythme de l'oralité aux lettres imprimées immobiles : les dernières pages du livre ne comportent que quelques lignes chacune, disposées diversement, le flux se tarissant peu à peu ${ }^{211}$.

L'écriture, même lorsqu'elle est encore imprimée sur papier, tente désormais de se montrer comme imprégnée du rythme de production des discours, si continu désormais. Ce rythme se marque jusqu'à la production journalistique : les articles en ligne portent souvent l'heure de leur publication, et de leur mise à jour. Ils prennent place rapidement, à la minute qui leur est dévolue, dans le flux continu des informations. Cet impact de l'oralité dans le rythme d'écriture se retrouve dans certaines remarques des auteurs qui ont écrit dans une culture où le discours oral était le vecteur principal de communication. Etre un «scripteur orateur », c'est bien ce qu'on lit par exemple chez l'auteur chrétien Origène ( 3 ème siècle), dans son commentaire de l'Evangile de Jean, comme le signale Corinne Egasse :

A l'occasion, Origène donne des indications sur le caractère spontané de son travail. « J'expose ces idées après coup, car elles se sont présentées à moi après avoir dicté ce qui précède ; nous gardons ainsi l'ordre même de ce qui m'est venu à l'esprit » (VII, 74). On devine presque auprès de lui la présence des tachygraphes employés par Ambroise... Il signale qu'il a

208 Derrida, « Philosophie et littérature : envie de faire les deux à la fois », 15/12/98, 16min51 à $17 \min 45$; $\quad<$ https://www.franceculture.fr/2016-01-20-l-ecriture-a-la-trace-a-voix-nuejacques-derrida-25>.

209 Voir point 2.1 ci-dessus.

210 M. Skalova, Exploration du flux, Seuil, 2018.

211 Skalova, Exploration du flux, p. 53-66. 
anticipé son commentaire : «à cela nous avons répondu partiellement

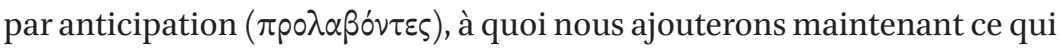
suit » (IX, 105). On sent par là le caractère spontané et vivant de son exégèse dictée et l'emballement ponctuel de sa pensée dont il reprend ensuite le contrôle ${ }^{212}$.

L'auteur doit pondérer ici les rythmes de production orale et écrite, soumise tout entiers aux conditions matérielles de cette production. Aujourd'hui, l'oralité est de retour au sein des écritures, digitales ou non, dans des possibles et des jeux que nous ne faisons que commencer à découvrir. La complexité des transformations multimodales des expressions humaines devrait conduire à accorder la même attention à ce qui se joue entre écriture et images, à l'arrivée surabondante des images dans ce que nous lisons, alors même que nous n'avons pas été formés, ou très peu, à la lecture d'images. Et pourtant des auteurs d'importance ont travaillé ce thème bien avant que l'écriture digitale ne réclame sa place. Par exemple, Roland Barthes a été très sensible aux images, rédigeant en 1964 un article qui fera date sur la rhétorique de l'image ${ }^{213}$. Cette préoccupation ne l'a ensuite jamais quitté, ce dont Guillaume Cassegrain a rendu compte dans une monographie en $2015^{214}$.

Aux voix d'auteurs sensibles depuis longtemps au visuel s'ajoutent désormais la publication croissante d'explorations de cette dimension, en lien à l'utilisation des $\mathrm{SIG}^{215}$, mais aussi parfois comme redécouvertes de périodes historiques, notamment l'Antiquité, et ce jusque dans l'exégèse biblique ${ }^{216}$, sensible désormais aussi à l'oralité et à la performance ${ }^{217}$. Enfin, de nombreux projets en Digital Humanities marient consciemment deux ou trois des dimensions multimodales, comme le Baudelaire Song project, qui unit écriture et chansons $^{218}$. A voir l'effort d'enquête et d'analyse des plusieurs articles consacrés à la relation entre écriture et image dans le premier numéro des Cahiers $d^{\prime}$ Agora $^{219}$, on réalise que la recherche en humanités ne fait qu'entamer une

212 C. Egasse, Le lavement des pieds. Recherche sur une pratique négligée, Labor et Fides, 2015, p. 211. Cette thèse a été conduite sous ma direction.

213 R. Barthes, «Rhétorique de l'image », Continuum 4 (1964), p. 40-51.

214 G. Cassegrain, Roland Barthes ou l'image advenue, Hazan, 2015.

215 Voir par exemple T. Arnold - L. Tilton, Humanities Data in R. Exploring Networks, Geospatial Data, Images, and Text, Springer, 2015.

216 Voir par exemple Robbins - Melion (éd.), Art Visual Exegesis.

217 Voir par exemple Oestreich -Holland (éd.), Performance Criticism.

218 Baudelaire Song project, <https://www.baudelairesong.org/>.

219 Cinq articles y sont consacrés à la thématique « Quelle fabrique quand images et écriture se rencontrent? », Cahiers d'Agora : revue en humanités 1 (2018), <https://www.u-cergy.fr/ fr/laboratoires/agora/cahiers-d-agora/numero-1.html>. 
longue transhumance épistémologique et méthodologique jusqu'à avoir des sources multimodales entièrement citables, référençables, analysées et interprétées.

Il apparaît donc d'autant plus urgent de remettre à plat ce que je considère comme un raccourci épistémologique de Bernard Stiegler. Se réjouissant de la « troisième mémoire » constituée par la technique ${ }^{220}$, il proclame que ces hypomnèses deviennent aujourd'hui la condition même de la mémoire: « contrairement à Platon, nous pensons qu'il n'y a pas d'anamnèse sans hypomnèse, ou que l'extériorisation de la mémoire n'est pas la mort de celle-ci mais sa condition même ${ }^{221}$. Hypomnèses désormais surabondantes, puisque toute trace d'activité numérique est potentiellement liée à sa source, oralité, image, textualité incluses. Or c'est faire comme si une trace enregistrée parlait et faisait œuvre de mémoire, faisant fi de ce qu'exprimait Derrida avec l'adage « dès que je parle, je trahis », dès que je parle, dès que j'écris, dès que je produis une expression humaine, sous quelque modalité que cela soit.

Plus on enregistre, plus on peut perdre et oublier aussi ; plus on accumule de données et de métadonnées, moins on voit peut-être et moins on observe. L'usage des mémoires extérieures, rendues si faciles par la technologie, ne doit pas nous faire oublier leur ambiguïté inhérente à toute trace. On peut notamment évoquer ici les deux ouvrages magistraux de Juliette Volcler sur la manipulation sonore, Le son comme arme. Les usages policiers et militaires du son et Contrôle. Comment s'inventa l'art de la manipulation sonore. Ou encore, pour ce qui est de l'écriture, l'enquête de Philippe Artières, La police de l'écriture. L'invention de la délinquance graphique $\left(185^{2-1945}\right)^{222}$. Toute trace est livraison et la multiplication des lieux de « troisième mémoire » est synonyme pour les sciences humaines d'une complexification, doublée d'un no man's méthodologique pour ce qui concerne les sources multimodales.

En fin de parcours sur la thématique de la multimodalité de l'écriture et des expressions digitales, on se gardera d'une autre simplification : celle de croire que l'image va l'emporter. Ce sera peut-être vrai dans certains lieux culturels ou sociaux, dans certaines enquêtes ou analyses. En revanche, certainement pas en ce qui concerne le langage informatique, ce miroir ou ce revers de l'écriture que nous pratiquons. En ce qui concerne le code, on ne peut pas déplorer la «pulsion scopique» de notre culture présente, pour laquelle il s'agirait, selon

\footnotetext{
220 Stiegler, « Dans la disruption », p. 216.

221 Stiegler, « Anamnèse », <http://www.arsindustrialis.org/anamnese>.

222 J. Volcler, Le son comme arme. Les usages policiers et militaires du son, La Découverte, 2011 ; J. Volcler, Contrôle. Comment s'inventa l'art de la manipulation sonore, La découverte, 2017 ; P. Artières, La police de l'écriture. L'invention de la délinquance graphique (1852-1945), La Découverte, 2013.
} 
Jean Romain, « de voir, de visualiser, de mettre l'accent sur l'écran qu'on a sous les yeux, de satisfaire notre appel au spectacle ${ }^{223}$. En effet, en régime informatique, l'interface en ligne de commande ${ }^{224}$ (CLI) l'emporte en précision et efficacité sur l'interface graphique ${ }^{225}$ (GUI). Autrement dit, lorsqu'on commence à ouvrir ce que nous ressentons comme la boîte noire de l'informatique et qu'on s'aventure dans les langages de programmation, l'écrit l'emporte bel et bien sur l'image : ce que vous pouvez faire en écrivant via le terminal de votre ordinateur sera toujours plus précis et rapide qu'en utilisant l'interface graphique de votre ordinateur.

Devant le code écrit - celui en lettres, et en amont celui en chiffres - le pouvoir de l'image se retire brusquement, et c'est comme un monde de scribes contemporains qui se révèle lorsqu'on ouvre la « boîte noire » de l'écriture digitale encodée, sœur jumelle de cette écriture que nous lisons à l'écran. Qui n’a pas encore fait l'expérience d'aller sur le terminal de son ordinateur pour le voir autrement devrait le faire d'urgence : taper, en code Unix ou autre, quelques mots pour communiquer en CLI à son ordinateur appartient aux étapes de démystification de notre relation à cet objet, et à ce que nous rêvons encore par trop de le voir envoyer sur le cloud. Avec Kenneth Goldsmith, nous sommes invités à prendre la mesure de l'effet du code et du pouvoir des lettres du code : « Les mots ne sont plus d'abord des conteneurs transparents ; leur teneur matérielle doit être prise en compte tout aussi bien. La page devient une toile, où le négatif des espaces entre les mots prend autant d'importance que les lettres elles-mêmes $»^{226}$.

Au fil des années, via mon expérience professionnelle à l'Institut Suisse de Bioinformatique, il est devenu de plus en plus clair pour moi que le code électronique devait compter comme langage, comme écriture à part entière, comme annoncé au chapitre 1. On y a vu que Domenico Fiormonte a souligné que l'encodage « implique la sélection d'un ensemble de possibilités et consiste donc en un geste interprétatif $»^{227}$, cette interprétation qu'Yves Citton désigne comme qualification clé des compétences humanistes ${ }^{228}$. Cette part interprétative du code se voit même à l'œil nu en observant les commentaires qu'il faut souvent ajouter au code pour qu'il soit compris, comme dans cet exemple issu de l'équipe italienne d'EvT (figure ci-dessus). On est ici visuellement proche

223 Romain, «La priorité pour l'école n'est pas d'enseigner le numérique », <https://www.le temps.ch/opinions/jean-romain-priorite-lecole-nest-denseigner-numerique $>$.

$224<$ https://fr.wikipedia.org/wiki/Interface_en_ligne_de_commande>.

225 <https://fr.wikipedia.org/wiki/Interface_graphique>.

226 Goldsmith, L'écriture sans écriture, p. 27.

227 Fiormonte, « The Digital Humanities », p. 30 ; cité au chapitre 1, p. 26.

228 Citton, L'Avenir des Humanités, p. 21 ; cité au chapitre 1, p. 26. 


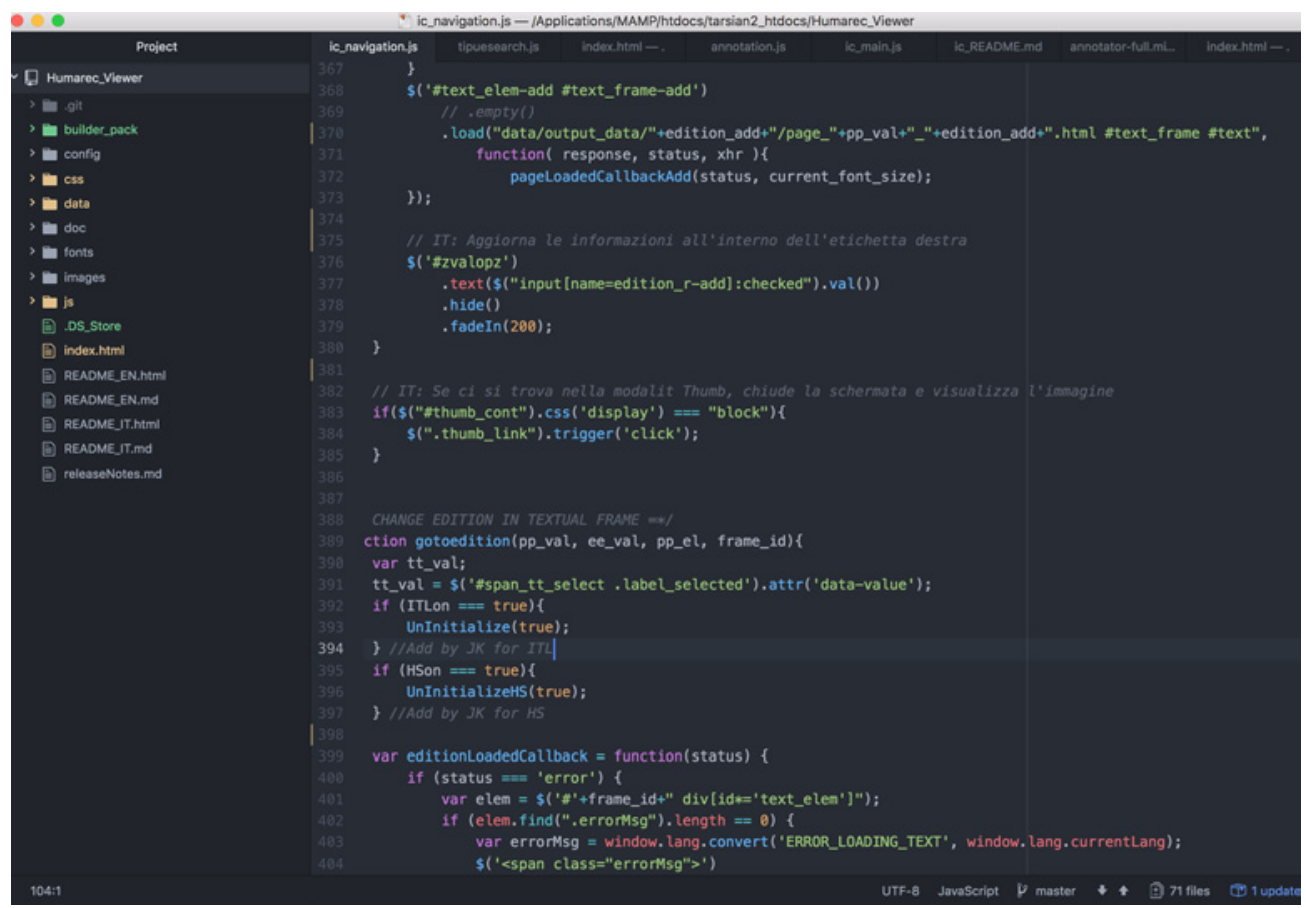

FIGURE 1 Auteurs : Equipe EVT, dir. Roberto Rosselli del Turco, page de code avec commentaires en italien

(C) REPRODUIT AVEC L'AUTORISATION D'EVT

des commentaires qui pouvaient entourer le texte dans des pages de manuscrits, comme par exemple dans le Codex Zacynthius, évoqué en 4.1229. On peut reprendre ici la lecture de Ion de Platon (2.2) et se demander si codeurs et écrivains, humanistes et informaticiens, DHers et bioinformaticiens ne sont pas d'un même geste des «interprètes d'interprètes » (Ion 535a), selon le mot quelque peu méprisant de Socrate adressé à Ion.

Ce dernier acquiesce avant d'avoir entendu par le philosophe la charge qui suit : « Car ce n'est ni un savoir technique ni une science qui te permet de commenter Homère comme tu le commentes : c'est un partage divin et une possession ${ }^{230}$. Embobinant le brave Ion dans sa maïeutique, le dialogue s'achèvera sans que celui-ci n'ait eu la moindre occasion de faire entendre à Socrate l'un de ses commentaires d'Homère, et Socrate lui fera réciter un passage de l'Iliade qui se conclut par «mais ne va pas toucher la pierre $!{ }^{231}$. Jolie mise en abyme

229 Voir p. 129 ci-dessus.

$230 \quad$ Platon, Ion 536c, p. 51.

231 Platon, Ion 537b, p. 53, citant l'Iliade 23, 335ss. 
de la pierre d'Héraclée, précisément utilisée par Socrate comme symbole de la possession du commentaire. Et si le commentaire, malgré tout, était une technique ? Et si nous avions mal évalué un certain nombre de paramètres de la culture digitale et de l'encodage en vertu de la « répulsion de la pierre d'Héraclée », comme j'ai intitulé ce sentiment transmis dans notre culture par la veine platonicienne ${ }^{232}$ ?

Se livrer à l'exercice à la fois évident et complexe de considérer d'un même regard les techniques du commentaire en sciences humaines et dans le code informatique appartient à la lutte contre cette répulsion, qu'il convient de mener à mon sens, sauf à vouloir demeurer sidérés par le cloud et sa culture. Cette lutte conduit à apprivoiser le lieu de l'écriture digitale, qui fait de l'écriture « une expérience flexible, évolutive, faite de pixels semblables à des cellules nageant en éprouvette. Il faut prendre soin de cette écriture pixellisée, depuis sa production et sur la durée. Elle est vivante, dans son environnement virtuel $»^{233}$.

En conséquence, pour un projet en sciences humaines développé dans un Virtual Research Environment en accès ouvert, il conviendrait de mettre sur GitHub $^{234}$ non seulement le matériel encodé vu comme propre au travail humaniste - le « contenu » de la recherche - mais aussi le code utilisé pour l'ensemble des parties du projet, également celles vues comme « techniques » ou « technologiques » et qui participent à la recherche et à l'écriture digitale de l'ensemble du projet. Un pas symbolique important vient du reste d'être franchi dans le sens de l'accession de l'écriture du code comme écriture à part entière : l'UNESCO et l'INRIA ont présenté le 7 juin 2018 un projet désigné comme «la bibliothèque d'Alexandrie des codes sources », ou Software Heritage $e^{235}$, qui en une année a regroupé déjà plus de 4 millions de codes sources. Son directeur, Roberto di Cosmo, le présente ainsi :

On utilise des logiciels tout le temps aujourd'hui, mais on se pose rarement la question de savoir comment ils sont «écrits». Ces logiciels sont écrits dans des langages de programmation, conçus pour être compréhensibles à la fois par des développeurs, et par les machines. Cela a environ $5^{0}$ ans, c'est assez récent, et on n'a pas pu s'y habituer comme

232 Voir le point 2.2 ci-dessus.

233 C. Clivaz, « De l'encre aux pixels : la mue de l'écriture scientifique », Le Temps 11 août 2017, $<$ https://blogs.letemps.ch/claire-clivaz/2017/08/11/de-lencre-aux-pixels-la-mue-delecriture-scientifique $/>$.

234 <https://github.com/>: «GitHub is a development platform inspired by the way you work. From open source to business, you can host and review code, manage projects, and build software alongside millions of other developers ».

Software heritage, <https://www.softwareheritage.org/>. 
on l'a fait avec des domaines comme la physique ou la biologie, qu'on connaît depuis des siècles. La plupart des gens ne sont pas encore capables de lire et d'apprécier cette connaissance, même si c'est en train de changer, il y a des initiatives dans les écoles pour mettre en place des cours d'informatique et de programmation. Ca change doucement. [...] L'archivage pour les livres, les peintures, les œuvres d'art, tout cela existe déjà, et il existe même une archive de tout l'historique des pages web, mais pas pour les codes sources. C'est étonnant, car les codes sources représentent la clé de la révolution numérique. Je pense qu'on n'y a tout simplement pas pensé avant ${ }^{236}$.

Par ailleurs, porter un regard global sur le code comme une écriture et un langage à part entière pourrait par ailleurs conduire à donner au moins les bases du code à tous les écoliers, dans le souci d'étendre la culture générale sur certains mécanismes de la boîte noire informatique. On aurait alors intégré en partie l'approche décapante de la mathématicienne diplômée de Harvard, Cathy O'Neil, qui explique de quelle manière les big data augmentent les inégalités et manipulent la démocratie ${ }^{237}$.

Emmener les élèves dans les dédales du code, même de manière basique, ne fait toutefois pas encore l'unanimitée ${ }^{38}$. Dans son blog du Temps, Blaise Reymondin rappelle qu'au début des années 80, en Suisse romande, les jeunes ados que nous étions ont pu suivre des cours de programmation, mais pour autant ne croit «pas que ce soit un prérequis aujourd'hui ${ }^{239}$. Or c'est justement parce qu'on a cessé d'enseigner des bribes de programmation à l'école que nous nous sommes tous éloignés - et les femmes en particulier ${ }^{240}-$ des

236 P. Montet, «'Nous créons la bibliothèque d'Alexandrie du code source' », Usbeck \& Rica, 16 juin 2018, <https://m.usbeketrica.com/article/nous-creons-la-bibliotheque-d-alexan drie-des-codes-sources $>$.

237 C. O'Neil, Weapons of Math Destruction. How Big Data Increases Inequality and Threatens Democracy, Broadway Books, 2016; voir pour l'entier de l'argumentation C. Clivaz, «L'Ecriture au risque du code : Réforme, an 501 », Le Temps 1er novembre 2016, <https:// blogs.letemps.ch/claire-clivaz/2016/11/01/lecriture-au-risque-du-code-reforme-an-501/ >.

238 Voir Romain, «La priorité pour l'école n'est pas d'enseigner le numérique », <https:// www.letemps.ch/opinions/jean-romain-priorite-lecole-nest-denseigner-numerique>.

239 B. Reymondin, « Le numérique trouve sa place au cœur de l'enseignement (au-delà de la programmation) », Le Temps 31 octobre 2016, <https://blogs.letemps.ch/blaise-reymon$\operatorname{din} / 2016 / 10 / 31 /$ le-numerique-trouve-sa-place-au-coeur-lenseignement-au-dela-de-laprogrammation/>.

240 M. Guzdial, « NPR When Women Stopped Coding in 1980's: As we repeat the same mistakes ", Computing Education Research Blog, <https://computinged.wordpress.com/ 2014/10/30/npr-when-women-stopped-coding-in-1980s-are-we-about-to-repeat-thepast $/>$. 
a priori de cette culture informatique. Il y a là une dynamique négative qui s'est enclenchée et qu'il faut contrer. Affirmer, comme Reymondin, que «les écoles doivent former sans tarder les étudiants à devenir des coaches d'intelligence artificielle $»^{241}$, mais sans leur permettre, un tant soit peu, d'être critiques face à cette forme d'intelligence en ayant une idée au moins générale de ce qu'est le code, l'algorithme, ne fait pas sens.

Le défi est en effet de permettre au plus grand nombre de citoyens possible de rester critiques face à la culture numérique, de ne pas perdre leur «puissance de sujet », selon l'expression d'Antoinette Rouvroy, dans ce monde complexe et complexifié, et particulièrement lorsque le code enthousiasme. Le 9 mai 2018, Philipp Meier écrivait dans la Neue Zürcher Zeitung, dans un grand article sur la notion de code :

Les codes sont-ils finalement la clé de tout, de notre théâtre du monde tout entier, pour ainsi dire? Je crois que oui. Et en cela, Facebook est seulement une petite comédie qui nous montre que nous ne sommes rien d'autre que des corps de données, composés d'informations. Mais le grand drame, que nous mettons en scène depuis nos pensées humaines, est autre : nommons-le « Roméo et Juliette ». Car en dernier ressort il en va finalement d'un seul code : notre propre code, c'est-à-dire le code génétique ${ }^{242}$.

Vouloir charger la notion de code d'être «la clé de tout » et la faire culminer dans le code génétique demande d'être analysé avec du recul et de la circonspection. Personne n'est en train de vendre des « clés » en amenant du code, informatique ou génétique : c'est plutôt à chaque étape une complexification du savoir qui s'annonce, en même temps que de nouvelles découvertes. Il faut prendre le temps de considérer avec Frédéric Schütz que la publication en lettres imprimées du code génétique d'une seule personne équivaudrait à

241 B. Reymondin, «Tous dresseurs d'intelligence artificielle ?», Le Temps 11 mai 2018, $<$ https://blogs.letemps.ch/blaise-reymondin/2018/05/11/tous-dresseurs-dintelligence-ar tificielle/>.

242 P. Meier, « Der Code ist unsere Wahrheit. Fabeln werden zu Formel - und wir selber sind nichts als verschlüsselte Datenträger », NZZ 9 Mai 2018, p. 41 : «Sind Codes also letztlich der Schlüssel zu allem, zu unserem ganzen Welttheater sozusagen ? Ich denke schon. Und Facebook ist darin nur eine kleine Komödie, die uns zeigt, dass wir nichts als numerische Datenkörper sind, bestehend aus Informationen. Das grosse Drama aber, das wir vollführen seit Menschengedenken, ist ein anderes : Nennen wir es 'Romeo und Julia'. Denn bei allem geht es schliesslich nur um eines : um unseren eigenen Code, nämlich den genetischen ». 
quinze années de publication du journal Le Temps ${ }^{243}$ ! Par ailleurs, Bertrand Kiefer, dans un éditorial de la Revue médicale suisse, alerte sur la complexité grandissante de nos représentations et perceptions de l'ADN, car le modèle consacré des quatre lettres ne semble plus suffire à le décrire : «Les humains ont aimé considérer l'ADN comme un texte, qui devait se lire de la même façon que tout écrit. Or non: les brins d'ADN ne cessent de se référer à leur propre structure, ils sont organisés en métatextes, boucles étranges et enchevêtrements superposés $»^{244}$.

De fait, une remarque similaire, parallèle, complémentaire, pourrait être faite à propos de l'écriture digitale. Devenue architextualité, elle s'enchevêtre en boucles et hyperliens, perdant la linéarité obligée des lettres de la culture imprimée. Le travail commun, interdisciplinaire, s'avère ici crucial pour qu'aucun des pans du savoir ne croie à la simplification des modèles de l'autre, à l'émergence de "clés », de solution, de grands codes capables de tout résu$m^{245}$. Les sciences humaines et les humanités digitalisées auront notamment pour tâche de rappeler sans cesse la densité du système symbolique, historique et sémantique, qui est mis en branle à chaque fois qu'on sollicite des mots, des expressions. Par exemple, le $17^{\mathrm{e}}$ colloque Wright, à l'Université de Genève en 2016, était intitulé Décoder le livre de la vie. La révolution génomique $^{246}$.

D'entrée, l'expression « décoder le livre de la vie » retient l'attention du philosophe Peter Sloterdijk, l'un des conférenciers, qui déploie les enjeux de la thématique en lien à l'écriture et au divin : « On a l'impression que l'on se rapproche aujourd'hui des intuitions des kabbalistes du XIII ${ }^{\mathrm{e}}$ siècle, qui pensaient que Dieu écrivait le monde. L'alphabet dont il se sert ne serait pas humain, mais génomique. Chez les généticiens, il y a une intuition spontanée, presque irrésistible, à parler du travail sur le génome comme d'une 'écriture'. D’ailleurs, ils ont recours aux métaphores de l'écriture classique pour qualifier leur activité : 'écrire', 'réécrire', 'corriger', 'déchiffrer le livre de la vie'... »247. Dans ces quelques phrases, on perçoit comment écriture et génomique se mêlent et s'entremêlent dans nos tentatives - toujours partielles et limitées - de décrire

243 F. Schütz, Médecine personnalisée: patient vs génétique, risques et probabilités, eTalk 3 mars 2016, зів Institut Suisse de Bioinformatique, <https://etalk.sib.swiss/?dir=schutz\#18>.

244 B. Kiefer, « Nouveaux concepts : tout se complique», RMS 14/602 (2018), p. 816, <https:// www.revmed.ch/RMS/2018/RMS-N-6o2/Nouveaux-concepts-tout-se-complique>.

245 Voir chapitre 4, points 1.3 et 2.1.

246 Colloque Wright 2016: Décoder le livre de la vie. La revolution génomique, <https://colloque. ch/wp-content/uploads/2018/o7/programmeA5_2016.pdf >.

247 J. Burri, «Entretien: Peter Sloterdijk: 'On a toujours éliminé les surhommes' », Le Temps 18 avril 2017, <https://www.letemps.ch/culture/peter-sloterdijk-on-toujours-elimine-sur hommes>. 
le vivant et le monde. L'aspiration à la « lecture totale » se retrouve de part et d'autre, divine et mystique dans le cas de la kabbale, holistique et scientifique dans le cas de la génomique.

C'est ici que la boîte de résonance théologique et biblique est nécessaire pour saisir la complexité de ce que l'on met en route avec les mots. En effet, le « livre de vie », expression véhiculée dans notre culture principalement par le livre de l'Apocalypse, a des « allures plutôt inquiétantes : on peut en être effacé ou non (Ap 3,5), et un 'étang de feu' est promis à ceux qui en seraient retirés (Ap 20,15) . [...] Proclamer qu'on décode - enfin ? - le livre de vie pourrait donc trahir en négatif notre crainte profonde devant cette génomique apprentie sorcière », comme je l'exprimais en $2016^{248}$.

Saisir la complexité de la transformation digitale de l'écriture et des développements de pointe de la génomique demandera dans un proche avenir un travail interdisciplinaire serré, fructueux et nécessaire. Ce point espère en avoir montré la pertinence. En effet, tant la multimodalité que le code, ces nouvelles aventures dont hérite l'écriture digitale, conduisent au corps, au vivant. L'écriture digitale rejoint ainsi ce rêve dont Derrida faisait part en conclusion de son interview Le papier ou moi, vous savez... :

Car d'autre part, je souffre aussi, jusqu'à la suffocation, d'un trop de papier, et c'est un autre spleen. Un autre soupir écologique. Comment sauver le monde du papier? Et son propre corps ? Je rêve donc aussi de vivre sans papier - et cela sonne parfois à mes oreilles comme une définition de la « vraie vie », du vivant de la vie. [...] Ne comptons pas les livres. Le papier, donc, m'expulse - hors de chez moi. Il me chasse. Cette fois, c'est aut aut : le papier ou moi $^{249}$.

A l'issue de cet article interview où Derrida a tant explicité et illustré le séisme engendré par la sortie du papier, ce papier qui nous tient au corps, il est assez sidérant, de le voir, en finale, non seulement rêver de vivre sans papier, mais se sentir aussi expulsé par lui, et réclamer l'alternative aut aut, le papier ou lui. Notre expulsion du papier est bel et bien en route désormais, et chaque jour davantage, mais tient-elle toujours du rêve et conduit-elle au «vivant de la vie »? Nous voici vingt ans plus tard face à de nouveaux doutes, notamment parce que le soupir écologique signalé par le philosophe s'est transformé : c'est

\footnotetext{
248 C. Clivaz, «Décoder le livre de la vie : des personnes et de la médecine », Le Temps 15 novembre 2016, <https://blogs.letemps.ch/claire-clivaz/2016/11/15/decoder-le-livre-de-lavie-des-personnes-et-de-la-medecine/>.

Derrida, « Le papier ou moi », p. 57.
} 
bien l'empreinte énergétique causée par le support d'écriture digitale qui nous inquiète à présent ${ }^{250}$. Mais qu'on la voie comme rêve ou cauchemar, notre expulsion du papier est de plus en plus prégnante. Reste le défi pour nous tous, en tant qu'individus, groupes, communautés, sociétés, de nous situer dans cet aut aut dont la radicalité ne saurait nous échapper.

Arrivés au terme de cette odyssée à la rencontre de l'écriture digitale, ou digital writing, revenons en conclusion à l'énoncé de Derrida posé comme questionnement de départ dans lintroduction de ce chapitre. Arpentant durant toute son existence la thématique de l'écriture, Derrida avait-il raison de désigner le corps comme horizon de l'action des nouvelles technologies, ce «nouveau rapport du corps de l'homme aux machines » ? Et est-ce bien le corps aussi qui se manifeste aux détours des extensions de cette technologie nouvelle qu'est l'écriture digitale? La résistance du français à traduire par un terme évident embed - enclore, incorporer, encastrer, encapsuler, insérer - signale-t-elle qu'il se joue quelque chose en profondeur pour cette écriture digitale dans les alliances qu'elle contracte à différentes matières, corps inclus ? Tout le parcours de ce chapitre invite à répondre par l'affirmative à ces questions, du moins à y tendre.

Nous avons vu que dès son premier écrit, Derrida pense l'écriture en fonction d'un lieu, en l'occurrence l'Origine de la géométrie d'Husserl, quand bien même il n'y thématise pas encore l'impact du support de l'écriture sur cette dernière. Nous avons vu ensuite que la force d'attraction de la culture digitale tend à rendre visible la part d'oralité de l'écrit, via les nombreuses formes de mémoire extérieure, d'hypomnèses, qu'elle permet, comme Stiegler le dit en reprenant Platon ${ }^{251}$. Au point 2.1, la comparaison entre un passage oral d'une interview de Derrida et sa version écrite publiée, montre, par sa forme et son contenu, le hiatus infini qui peut se tenir entre oralité et écriture. En effet, la version orale, première, fait entrer la parole dans l'écriture, points de suspension inclus : «Cette confession, à savoir je suis en train... dès que je parle, je trahis. [...Et] c'est à cette condition qu[e la trace] devient littérature ${ }^{252}$.

\footnotetext{
$250 \quad$ Voir p. 130 ci-dessus.

251 Voir point 2.1 ci-dessus.

252 J. Derrida, « Philosophie et littérature : envie de faire les deux à la fois », 15/12/98, 16min 51 à $17 \min 45 ; \quad<$ https://www.franceculture.fr/2016-01-20-l-ecriture-a-la-trace-a-voix-nuejacques-derrida-25>.
} 
Les nouveaux possibles informatiques conduisent également à rendre sa place à l'oralité jusque dans le code Unix (2.1) et la note de bas de page (4.2 $)^{253}$. Ils nous rendent attentifs aux rythmes des différentes productions de l'expression humaine. Pétri d'oralité et de rythmes, le lieu digital de l'écriture, pour être appréhendé, demande de surmonter notre appréhension face à la pierre d'Héraclée, représentant la matière magnétique, qu'il s'agit d'oser aller toucher contrairement à l'ordre de l'Iliade que Socrate s'arrange à faire prononcer à Ion ${ }^{254}$. Ce toucher de l'objet digital nous modifie bel en bien profondeur, comme le prouvent des recherches en biologie sur l'impact de l'usage des smartphones sur notre cerveau ${ }^{255}$. Nous voilà devenus poreux, à la matière digitale, bien plus qu'hybrides.

Impactant jusqu'au corps, le lieu digital de cette écriture nouvelle se laisse comparer à la khôra antique, « ce tritos genos qui met à l'épreuve le politique, qui nous est 'comme' une mère tantôt nourricière, tantôt dévorante, 'comme' une empreinte-réceptacle ni sensible, ni intelligible » ${ }^{256}$. Ce lieu met au défi les « je » d'auteurs, historiens, écrivains, poètes, journalistes ou simples quidam, en les livrant à l'expérience de la porosité et de la collectivisation ${ }^{257}$. Alors qu'on nous annonce déjà le brainjacking et l'armada juridique pour s'en prémunir, émerge alors le désir de l'ultime résistance de la " puissance du sujet » dans ce qu'il pourrait bien rester de nos fors intérieurs ${ }^{258}$.

Dans ces circonstances, il ne faudra pas manquer de courage pour relire Sarraute et sa méditation du for intérieur, en l'associant à ce que Katherine Hayles a désigné comme l'impensé, le unthought. C'est dans le monde des tropismes, entre les sensations corporelles et les mots, là où le casque AlterEgo prétend agir, que nous pourrons peut-être défendre notre périmètre ultime. Le for intérieur se dit en réponse et résistance au « for extérieur ou externe, soit 'l'autorité de la justice humaine s'exerçant sur les personnes et sur les biens'» ${ }^{259}$. Face à la juridiction de la gouvernementalité algorithmique, «le for intérieur semble donc bien être, quant à lui, ce qui n'est pas soumis au for extérieur de cette gouvernementalité ; il peut donc se donner comme le lieu à cultiver pour développer la puissance du sujet malgré tout, et sa non-coïncidence aux prédictions faites sur les sujets $»^{260}$. Le lieu de l'écriture digitale, dans le jeu entre for

\footnotetext{
253 Voir points 2.1 et 4.2 ci-dessus.

254 Platon, Ion 537 b, p. 53, citant l'Iliade 23, 335ss ; cité au point 4.3 ci-dessus.

255 Voir point 2.2 ci-dessus.

256 Voir point 2.2 ci-dessus.

257 Voir point 3.2 ci-dessus.

258 Voir point 3.2 ci-dessus.

259 Voir au point 3.3 la discussion autour du for intérieur.

260 Rouvroy, « La vie n'est pas donnée », p. 198 ; cité p. 121 ci-dessus.
} 
extérieur et intérieur, est donc bien aussi un tritos genos politique, où les personnes peuvent se faire elles-mêmes Human library ou Living library, accomplissant ainsi dans leur chair le roman Fahrenheit 457.

Si la prise de congé du dispositif de la couverture congédie un registre important de rapport au corps, ce dernier reprend ses droits par la prégnance de l'oralité regagnée, à travers de nombreux exemples donnés dans ce chapitre 3 , notamment le logiciel Audacity qui suit le souffle de l'orateur pour découper un discours, ou dans la mise en page même d'Exploration du flux de Marina Skalova ${ }^{261}$. Liant textes, images et sons, la multimodalité de l'écriture digitale l'invite à toutes sortes d'expériences d'embedment avec les sens et la corporéité. Quant au code électronique, cette nouvelle grammaire de l'envers de l'écriture digitale, il est proche de son cousin le code génétique : complexification de l'écriture de l'ADN et de l'écriture digitale vont de pair, jusqu'aux premières expériences de stockage de données dans de l'ADN ${ }^{262}$.

Si l'écriture digitale appartient donc aux technologies qui désignent un nouveau rapport du corps de l'homme aux machines, que devient en conséquence l'appareillage symbolique des Ecritures dites bibliques, chrétiennes en particulier, lorsqu'elle s'unissent à la khôra digitale ? Elles ont en effet tant usé de la double symbolique des Ecritures et du corps, ou du corps des Ecritures. Que devient ce corps des Ecritures une fois livré à l'écriture digitale ? Telle sera l'enquête du dernier chapitre de ce livre.

261 Voir point 4.3 ci-dessus.

262 Voir point 4.3 ci-dessus. 